\title{
The downside of downtime: The prevalence and work pacing consequences of idle time at work
}

\section{Citation}

Brodsky, Andrew and Teresa M. Amabile. "The downside of downtime: The prevalence and work pacing consequences of idle time at work." Journal of Applied Psychology (forthcoming).

\section{Permanent link}

http://nrs.harvard.edu/urn-3:HUL.InstRepos:34609599

\section{Terms of Use}

This article was downloaded from Harvard University's DASH repository, and is made available under the terms and conditions applicable to Open Access Policy Articles, as set forth at http:// nrs.harvard.edu/urn-3:HUL.InstRepos:dash.current.terms-of-use\#OAP

\section{Share Your Story}

The Harvard community has made this article openly available.

Please share how this access benefits you. Submit a story.

\section{Accessibility}


Forthcoming in the Journal of Applied Psychology

The downside of downtime:

The prevalence and work pacing consequences of idle time at work

\author{
ANDREW BRODSKY (Corresponding Author) \\ The University of Texas at Austin \\ Andrew.Brodsky@mccombs.utexas.edu
}

\author{
TERESA M. AMABILE \\ Harvard Business School \\ tamabile@hbs.edu
}

Author Note: An earlier version of this work was presented at the $73^{\text {rd }}$ Annual Meeting of the Academy of Management in Orlando, Florida. We thank Stephanie Fazio, Ista Zahn, Gabe Mansur, Joshua Margolis, Francesca Gino, Subra Tangirala, Adam Grant, Kavya Shankar, Ting Zhang, and the OB Lab at Harvard Business School for their assistance and advice throughout the development of this article.

(C) 2017, American Psychological Association. This paper is not the copy of record and may not exactly replicate the final, authoritative version of the article. Please do not copy or cite without authors permission. The final article will be available, upon publication, via its DOI: 10.1037/apl0000294 


\section{The downside of downtime:}

\section{The prevalence and work pacing consequences of idle time at work}

\section{ABSTRACT}

Although both media commentary and academic research have focused much attention on the dilemma of employees being too busy, this paper presents evidence of the opposite phenomenon, in which employees do not have enough work to fill their time and are left with hours of meaningless idle time each week. We conducted six studies that examine the prevalence and work pacing consequences of involuntary idle time. In a nationally representative crossoccupational survey (Study 1), we found that idle time occurs frequently across all occupational categories; we estimate that employers in the United States pay roughly $\$ 100$ billion in wages for time that employees spend idle. Studies 2a-3b experimentally demonstrate that there are also collateral consequences of idle time; when workers expect idle time following a task, their work pace declines and their task completion time increases. This decline reverses the welldocumented deadline effect, producing a deadtime effect, whereby workers slow down as a task progresses. Our analyses of work pace patterns provide evidence for a time discounting mechanism: workers discount idle time when it is relatively distant, but act to avoid it increasingly as it becomes more proximate. Finally, Study 4 demonstrates that the expectation of being able to engage in leisure activities during post-task free time (e.g., surfing the Internet) can mitigate the collateral work pace losses due to idle time. Through examination and discussion of the effects of idle time at work, we broaden theory on work pacing.

Keywords: time; pacing; idle; deadline; Internet 
"It is the working man who is the happy man. Man was made to be active, and he is never so happy as when he is so. It is the idle man who is the miserable man.”-Benjamin Franklin (Wooléver, 1893)

In discussing time at work, most contemporary research (Beck \& Schmidt, 2013; DeVoe \& Pfeffer, 2011) and media commentary (Mantell, 2011; Quast, 2012) focus on the dilemma of employees having too much work to do in too little time. Contributing to this recent commentary is the goal of many companies to become "lean" by eliminating all slack (Arnheiter \& Maleyeff, 2005; Knight \& Haslam, 2010; Nieuwenhuis, Knight, Postmes, \& Haslam, 2014). The opposite of intense busyness - idle time in which no work is available - is rarely discussed. Recent examinations of downtime at work have been primarily limited to workers' own procrastination (Pierro, Giacomantonio, Pica, Kruglanski, \& Higgins, 2011; Steel, 2007) and to breaks, which are periods of downtime during which work is available but is not expected to be done (Jett \& George, 2003; Sonnentag, 2001; Trougakos, Hideg, Cheng, \& Beal, 2013).

Ongoing shifts in the global labor market from production-based to service-based work (Gustafsson \& Johnson, 2003) have likely increased the type of downtime that is the focus of this paper: idle time. We define idle time as a period of involuntary downtime during which in-role tasks cannot be done. Many production jobs can be handled with limited slack or idle time (i.e., they can be "lean”), since organizations with such jobs have relatively high control over the rate of inflow of raw materials (Krafcik, 1988; Shah \& Ward, 2007). In contrast, the primary input for service jobs is moment-to-moment customer demand, which most organizations have little control over. Examples of service-sector idle time include call center agents waiting for customers to call during slow periods and investment bankers waiting for client information to build a model. Furthermore, there are additional drivers of idle time that extend well beyond the 
service sector, including managers inefficiently distributing work and spontaneous technical malfunctions preventing work completion. Indeed, for employees such as parking lot attendants and nighttime security guards, experiencing idle time may even be part of the job definition itself. In management research, the existence of idle time at work was first directly addressed by Fisher (1993), when she found that 55\% of reported instances of work boredom involved "quantitative underload," or having too little work to do. Since that paper was published over 20 years ago, however, this topic has received little additional examination.

The presence and consequences of idle time at work have significant implications for both management practice and scholarly theory. The most obvious potential cost of idle time is the monetary cost associated with organizations paying employees for time when they are not doing any work. We begin our studies by first establishing the prevalence of idle time through a nationally representative employee survey (Study 1). We then test the consequences of anticipated idle time on employee work pace and overall task completion speed (Studies 2a-3b). In doing so, we extend pacing theory beyond its historically central focus on deadlines (Gersick, 1988; Mohammed \& Harrison, 2013; Seers \& Woodruff, 1997), and provide evidence of a new pacing behavior that we call the deadtime effect (Studies 2a-3b). We conclude our research by examining how the characteristics of post-task work time, specifically the expectation of being able to engage in leisure activities such as Internet surfing, can alter work pacing (Study 4). Taken together, these findings highlight a frequently experienced—but overlooked— phenomenon, and lay the foundation for a more comprehensive theory of work pacing.

\section{THE WORK PACING CONSEQUENCES OF IDLE TIME}

\section{Idle Time and Pacing Theory}

Idle Time. If the experience of idle time is widespread in contemporary organizations, 
this raises questions about whether and how worker behavior might be altered by it.

Theoretically, three aspects of idle time could affect worker behavior: the anticipation of idle time, the experience of idle time, and the aftermath of idle time. Although the consequences of the experience and aftermath of idle time are bounded by the actual quantity of idle time, the anticipation of idle time may be unbounded. A worker who experiences frequent idle time at work may be in a near-constant state of anticipating future idle time, which could have extensive effects on psychological state and work behaviors. For instance, a marketing analyst who knows that her manager tends not to assign enough work may anticipate idle time after nearly every task and alter her behavior accordingly, even if there is a chance that unexpected tasks may arise. Given that the anticipation of idle time may extend well beyond the bounds of idle time itself, we begin embedding this phenomenon into existing management theory by examining how workers might alter their pacing and, thus, their task completion time when anticipating idle time. To do so, we turn to theory on work pacing, which addresses how expectations about future events (usually deadlines) can alter the pace of work.

Pacing Theory. Given the central role of employee work speed in determining overall organizational productivity, management scholars have long been interested in developing theory on work pacing (Mitchell, Harman, Lee, \& Lee, 2008; Moore \& Tenney, 2012; Waller, ZellmerBruhn, \& Giambatista, 2002). Beyond simply the average work pace of employees, the more dynamic nature of work pacing has also been of interest, because work pace need not be constant across a task. Identifying and understanding the period of a task during which people are working most slowly is necessary for developing nuanced theories and practical interventions to ameliorate these lulls. Multiple studies have unearthed various pacing patterns, such as the deadline effect, whereby workers progressively speed up as a deadline approaches (Lim \& 
Murnighan, 1994); mid-point transitions, whereby workers tend to speed up suddenly at the midpoint of a task (Gersick, 1988, 1989); and U-shaped pacing, whereby work pace is fastest at the beginning and end of a task (Gevers, Mohammed, \& Baytalskaya, 2015; Gevers, Rutte, \& Van Eerde, 2006). Although a number of pacing patterns have been delineated (Gevers et al., 2015), research on these patterns generally shares one commonality: the assumption of tightly limited time to work, which causes workers to speed up (in some manner) as a deadline approaches. Prior research has offered far less insight into whether and how pacing behavior might be affected if there is more than enough time for a task and, thus, a worker expects idle time before a deadline.

Whereas studies of the deadline effect primarily examine high time pressure work, expected idle time is likely to be associated with more of a low time pressure context. The limited research on work pacing in low time pressure contexts generally focuses on Parkinson’s Law: "Work expands so as to fill the time available for its completion" (Parkinson, 1957). Most research on this topic compares tasks with low time pressure or no deadlines to tasks with moderate to high time pressure and finds that, in the absence of tight deadlines, people tend to work more slowly (Aronson \& Gerard, 1966; Bryan \& Locke, 1967; Latham \& Locke, 1975); we refer to this as work-stretching. The general assumption underlying these studies is that the primary external driver of employees’ work pace is a deadline (Bryan \& Locke, 1967; Latham \& Locke, 1975) and, in the absence of these deadlines, workers’ pace will be less externally driven; they will either proceed at a more constant, slower pace, or will work slowly until the deadline is near and then speed up as it approaches (Lim \& Murnighan, 1994). We argue that there is a fundamental difference between having too much time available to complete a task (as has been examined in prior studies of low time pressure) and being forced to experience idle time after 
finishing a task for which too much time is available. In the former case, external drivers of pacing are absent, but in the latter case, the specter of idle time may act as a strong external driver of pacing.

Idle Time and Pacing. Before discussing how and why expected idle time might alter work pacing, it is first important to consider why the answer to this question is meaningful for organizations. If employees are going to be idle anyway, then why should an organization care if they stretch out their work? Consider, however, the potential benefits of a certain amount of idle time in the work day—benefits documented in prior research. Idle time can enable employees to meet unexpected demand for their in-role work tasks or fulfill any unexpected extra-role tasks that may arise, such as unexpected opportunities for organizational citizenship behaviors (OCBs) (Amabile et al., 2002; Hui, Organ, \& Crocker, 1994). For instance, if an accounts payable clerk got a sudden, unexpected inflow of a large number of invoices to process, or was asked by a coworker to cover his work due to a family emergency, that clerk would only be able to properly complete the additional work if she had available time. However, if employees' natural tendencies are to stretch out their work in an attempt to reduce expected idle time, then that action would counteract any potential benefits of the idle time; that time simply would not be available.

Given the consequences that might ensue from pacing alterations - specifically, from work-stretching - due to expected idle time, it is important to consider why and how the expectation of idle time might alter work pacing behavior in this way. First, there are negative consequences of being seen as idle, even when the idleness is outside of the control of the individual employee. Research on the input bias (Chinander \& Schweitzer, 2003) and facetime (Elsbach, Cable, \& Sherman, 2010) provides strong evidence that managers' evaluations of 
individual employees are not only based on the objective quality of the work produced, but are also biased by how much time the manager observes the employee working. Accordingly, even if there is no performance quality benefit to stretching out work, employees might personally benefit from doing so. Furthermore, if managers observe an employee being idle too frequently, they may well come to the conclusion that the employee's role is unnecessary and that she should be let go. Considering these factors, it seems likely that employees mask their downtime, resulting in managers significantly underestimating the amount of time that their subordinates are not actively engaged in work (Malachowski, 2005).

Beyond normative pressures inside organizations, there are more fundamental psychological processes that could operate on individuals to alter their pacing behavior when they face the prospect of idle time. Across a number of different fields of research, there is consistent evidence that time spent idle or waiting is perceived as an aversive experience. Boredom, which is most frequently caused by work underload (Fisher, 1993), can have a wide variety of undesirable consequences, including lower job satisfaction (Kass, Vodanovich, \& Callender, 2001; Loukidou, Loan Clarke, \& Daniels, 2009; O'Hanlon, 1981), increased job withdrawal (Spector et al., 2006), and even decreased lifespan (Britton \& Shipley, 2010). Based in neurology, activation theory sheds light on why idle time is experienced as boring: although being overstimulated can hamper affective experience (as well as work quality), so, too, can being understimulated (Gardner, 1986; Robert \& John, 1908; Schlosberg, 1954). People thrive when they experience optimal cognitive arousal, but at low levels of activation/arousal, people tend not to be alert, their senses become dulled, and they often experience high levels of negative affect (Fiske \& Maddi, 1961; Scott, 1966). Marketing research on waiting has similarly shown that waiting for customer service, either on the phone or in 
physical queues, substantially increases negative affect and worsens service evaluations (Antonides, Verhoef, \& van Aalst, 2002; Houston, Bettencourt, \& Wenger, 1998; Taylor, 1994; Tom \& Lucey, 1995). In laboratory experiments, participants have even been willing to go as far as giving themselves shocks to help break up the negative experience of time spent idly waiting with only their own thoughts (Wilson et al., 2014). Given the highly aversive nature of idle time, we predict that workers will seek to avoid it. Consequently, we hypothesize that when workers expect idle time, they will engage in work-stretching - they will work more slowly - in order to simultaneously postpone and reduce the amount of idle time. This work-stretching will result in increased task completion time for workers who expect idle time, relative to workers with an identical task that involves the same work and deadline or time pressure, but no expected idle time.

Hypothesis 1: Workers who expect idle time following a task will take longer to complete that task than workers who do not expect idle time.

Time discounting and the deadtime effect. A central concern in pacing theory, beyond the average pace of work, involves the more dynamic patterns of pacing (Gersick, 1988; Waller et al., 2002). In the context of Hypothesis 1, the dynamism question asks: if employees stretch out their work under expected idle time, in what manner might they do so? Will they work more slowly at the beginning of the task, the end of the task, both, or consistently throughout? Beyond the practical value of identifying such dynamics, the pacing pattern is theoretically important because it could illuminate the mechanism by which work-stretching behavior results from expected idle time.

Time discounting is an overarching theoretical mechanism that sheds light on how workers would be expected to behave if, as we have argued, they are motivated to avoid idle 
time. At the core of the theory of time discounting is the idea that people undervalue their future (Ainslie, 1992; Critchfield \& Kollins, 2001; Samuelson, 1937; Steel \& König, 2006), such that temporally proximate events impact behavior much more strongly than temporally distant ones. This discounting process is most frequently assessed behaviorally - by demonstrating, for example, that people are willing to accept less money now rather than wait longer for additional money, beyond what would be considered a rational decision based solely on the interest rate (Green, Myerson, \& McFadden, 1997; Lerner, Li, \& Weber, 2012; Thaler, 1998). One of the most commonly cited examples of both shorter- and longer-term time discounting in the management literature is procrastination (Steel, 2007; Steel \& König, 2006). There may be a basic evolutionary mechanism underlying time discounting; it has even been shown to function in animals, in the very short-term, as a driving force behind the risks that animals take in their hunting and foraging patterns (Green \& Myerson, 1996).

In line with this logic, there is considerable evidence that people tend to choose pleasurable activities and outcomes in the short term, even when delaying would lead to a greater quantity of such activities and outcomes (Green, Fristoe, \& Myerson, 1994; Rachlin, Raineri, \& Cross, 1991; Trope \& Liberman, 2000). Similarly, people tend to postpone undesirable activities and outcomes in the short term, even when delaying leads to more undesirable activities and outcomes (König \& Kleinmann, 2004; Steel, 2007). The latter process has previously been incorporated into pacing theory as one of the primary drivers of procrastination (O'Donoghue \& Rabin, 1999; Steel, 2007). Existing research on the deadline effect (a linear increase in work pace) also relies on the underlying concepts of time discounting, with a particular focus on how closer deadlines drive employees to work more quickly, while more distant deadlines have limited impact on pacing (Gersick, 1988; Roth, Murnighan, \& Schoumaker, 1988). 
Drawing on time discounting theory, we expect that, if anticipated idle time does, indeed, lead to work-stretching because it is aversive, anticipated idle time will exert a stronger influence on behavior as it draws closer. When idle time is expected to occur in the relatively distant future, the importance of that aversive period of time will be psychologically discounted; consequently, it will have a minimal impact on behavior. However, as idle time draws near, toward the end of a task when little work remains, it will have an increasing impact on the degree to which workers act to limit or avoid idle time. Accordingly, we predict that people expecting idle time will slow down as the deadline approaches. Drawing a direct contrast to the deadline effect (whereby workers speed up throughout a task), we refer to this behavior of slowing down as idle time approaches as the deadtime effect.

Hypothesis 2a: Workers who expect idle time after a task is completed will slow down as the task progresses (and idle time approaches).

If workers anticipating idle time do slow down as a task progresses, then the question remains as to the pattern of that deceleration. The simplest such pattern would be a linear deceleration, which would be comparable to the often-observed linear acceleration associated with the deadline effect (Lim \& Murnighan, 1994; Waller et al., 2002). However, time discounting theory argues for non-linear discounting, in that the impact of anticipated future events increases more as they approach (Frederick, Loewenstein, \& O'donoghue, 2002; McClure, Ericson, Laibson, Loewenstein, \& Cohen, 2007; Thaler, 1998). For example, an employee is likely to be fairly unconcerned about - that is, discount - her year-end performance evaluation 11 months before it occurs, almost equally so from the beginning to the end of that month. But in moving from just the week before to the week of the evaluation meeting (a difference of only a few days), that same employee is likely to experience a notable increase in stress as the event 
looms larger. Even in the very short-term, minutes before the meeting (as compared to even the beginning of that day), the employee is likely to be much more apprehensive and alter her behavior accordingly (e.g., rapidly increasing the pace at which she tries to gather supporting evidence of her performance for the review). If time discounting is truly underlying the predicted deadtime effect, then we would expect that deadtime will have a significantly increasing impact on the rate at which workers' pacing behavior changes as the deadtime draws nearer. Accordingly, we hypothesize:

Hypothesis 2b: Workers who expect idle time after a task is completed will slow their work pace at an increasing rate (i.e., non-linearly) as the task progresses (and idle time approaches).

The processes we have discussed do not represent an overall change in effort under expected idle time, but rather a spreading of effort over a longer period (i.e., a reduction in pacing). Accordingly, we do not make any predictions regarding direct improvements or decrements to performance quality.

\section{Leisure Activities and Idle Time}

We have argued that a primary mechanism by which expected idle time could lead to work-stretching (the effect predicted in Hypothesis 1) is that workers will be motivated to avoid

idle time due to its aversive nature. As developed in the previous section, this mechanism would be supported by evidence of time discounting in the pacing behavior of people expecting idle time (as predicted in Hypotheses 2a and 2b). A different type of support for this mechanism would be evidence that making idle time more appealing (less aversive) decreases workstretching. In theorizing broadly about idle time, it is useful to consider that not all idle time need be purely idle - that it might be altered in some way. 
To this point, we have assumed that idle time lacks leisure activities and, thus, is truly “dead” time. There is a strong rationale for this assumption in many work contexts, because many organizations restrict employees from engaging in leisure activities, such as making personal calls or surfing the Internet, during the workday (Amour, 2006; Askew et al., 2014; Connor, 2013; Lim, 2002). Furthermore, even if leisure activities are available, employees may opt to limit their use for fear of being seen as expendable by a manager or inciting jealousy from coworkers who may be busier. These concerns are legitimate, as shown by research on the input bias and facetime, as previously discussed (Chinander \& Schweitzer, 2003; Elsbach et al., 2010). Further evidence that engaging in leisure activities at work is perceived negatively comes from the creation of the term “cyberloafing," which was coined to describe personal Internet use at work (Askew et al., 2014; Jia, Jia, \& Karau, 2013; Lim, 2002).

However, permitting leisure activities for employees during idle time should make it less idle and counteract the mechanism we have proposed. Sanctioned leisure activities could potentially offer an incentive to finish quickly, and could alter workers’ perceptions of idle time such that it comes to be viewed as more desirable. Together, these arguments suggest that the expected availability of leisure activities during idle time could at least partially mitigate the negative work pacing costs of expected idle time that is completely empty. Accordingly, we hypothesize that, when workers face idle time, the expected availability of leisure activities will result in faster task completion times relative to people who do not expect to be able to fill idle time with other activities.

Hypothesis 3: Workers who expect to experience empty idle time after finishing a task will take longer to complete the task than workers who expect to experience a period of idle time but are allowed to engage in leisure activities during that time. 
Testing this hypothesis both broadens our examination of idle time and further investigates the avoidance mechanism. When post-work time is less aversive, it should exert less impact on behavior and, thus, work pace should be higher and remain more constant throughout the task even as the post-work time approaches.

\section{STUDY 1}

Before investigating whether and how workers alter their behavior in response to expected idle time, we first examined whether idle time even exists in contemporary work life to an extent that it would routinely be anticipated by workers. Given that popular academic and media dialogues suggest that employees are busier than ever, it seems possible that idle time is only infrequently experienced, or in only a very limited set of occupations. Thus, our first study aimed to identify the frequency and quantity of idle time in the U.S. workforce.

\section{Methods}

Participants. Participants were recruited to be part of an online survey conducted by the survey firm GfK as part of GfK’s KnowledgePanel ${ }^{\circledR}$, a probability-based panel designed to be representative of the U.S. population. Participants cannot independently "sign up" to be part of the survey pool; rather, participants are randomly selected and recruited by GfK to ensure that the sample is representative of the U.S. population. The GfK survey panel has been frequently used as a means of obtaining nationally representative data across a variety of fields, including psychology (Lerner, Gonzalez, Small, \& Fischhoff, 2003; Seery, Holman, \& Silver, 2010), medicine (Eisenberg, Freed, Davis, Singer, \& Prosser, 2011; Harris, Schonlau, \& Lurie, 2009), and political science (Bailenson, Iyengar, Yee, \& Collins, 2008). The probability-based sample was recruited using a random selection of telephone numbers and residential addresses. Persons in selected households were then invited by telephone or mail to participate. For those who 
agreed to participate, but did not already have Internet access, GfK provided a laptop and ISP connection at no cost. Furthermore, to ensure that employment status did not create a response bias, the survey was conducted only during the weekend (i.e., after 5:00pm on Friday through Sunday). The survey was completed by 2,103 participants. Then, to correct for potential biases due to non-response, participant responses were weighted based on the U.S. census to be representative of the U.S. population for gender, age, race/ethnicity, education, census region, metro status, Internet access, and Spanish language. This step led to a weighted participant count of 2,000. Only those participants who indicated they were employed and worked primarily outside of the home $(n=1,003)$ were asked the questions regarding idle time. We only utilized respondents who worked outside of the home because idle time would be meaningfully different at home as opposed to a workplace. When people who work from home are idle, they can presumably just “leave” work (engage in a leisure activity) rather than remain idle.

Survey. We developed definitions of three types of downtime that were provided to participants:

1. Breaks. These are explicitly scheduled periods of time when you are not supposed to be working, like lunch break.

2. Self-Caused Downtime. This is unscheduled time when you personally decide not to engage in work for some reason (e.g., procrastination or a self-initiated break).

3. OTHER-CAUSED IDLE TIME. This is unscheduled time when you are unable to engage in work for your company for a reason beyond your control (e.g., there are no customers, your manager did not give you work, or you are waiting for a process to be completed).

To ensure that these definitions were understandable to the vast majority of people, a 
pilot study had previously been conducted on Amazon Mechanical Turk with 100 participants. After having read the definitions, the pilot participants were asked to indicate whether each of three separate examples was an example of idle time: (a) A factory worker not working because he is currently on a scheduled coffee break; (b) A help-desk employee not working because no one has come in with issues to fix, and she does not have any other tasks that she can begin on her own, and (c) A call center employee not working because he is using Facebook as a form of procrastination since he is not in the mood to work. Respectively, 98\%, 97\%, and 94\% of pilot participants correctly identified example A as not other-caused idle time, example B as othercaused idle time, and example $\mathrm{C}$ as not other-caused idle time. This high accuracy rate suggested that the vast majority—if not all—of participants could understand the definitions.

After the participants in the national survey received the definitions, they were asked two questions. The first was a multiple choice question that asked, "On average, how frequently do you experience periods of at least 15 minutes of other-caused idle time at your primary job?”, and allowed participants to choose a response ranging from "never" to "every day." Next, participants were asked: "During your previous 5 days of work in your primary job, approximately how much other-caused idle time did you experience at work?”

Additional demographic data provided by participants as part of their recruitment in the panel included employment status (full-time/part-time), occupational category, gender, age, household income, and education.

This study was approved by Harvard University’s Institutional Review Board, protocol number IRB15-2296 (Title: Idle Time Telephone Survey).

\section{Results and Discussion}

Figure 1 presents the weighted frequency of participants' reported other-caused idle time 
(which we henceforth refer to simply as "idle time"). The vast majority (78.1\%) of participants reported experiencing idle time. Furthermore, just as many participants reported having idle time every day (21.7\%) as reported never having idle time (21.7\%). In every one of the 29 occupational categories collected by GfK (e.g., management, farming/forestry/fishing, lawyer/judge, and armed services), which were based on the U.S. Census Current Population Survey's (CPS) categories, at least 50\% of respondents indicated that they experienced idle time.

\section{Insert Figure 1 Here}

The weighted mean amount of idle time that participants reported experiencing in the previous 5 days of work was 1 hour and 9 minutes [SD=201 minutes; 95\% CI: (55 minutes, 82 minutes)]. Excluding participants who reported no idle time in the previous 5 workdays, the weighted mean amount of idle time in the previous 5 days was 2 hours and 45 minutes [SD=285 minutes; 95\% CI (136 minutes, 195 minutes)].

As would be expected, the correlation between the frequency of idle time and quantity of idle time in the past 5 days was significant $(r=0.260, \mathrm{p}<.001)$. The quantity of idle time did not significantly correlate with age $(\mathrm{r}=-.005, \mathrm{p}=.887)$, education level $(\mathrm{r}=-.026, \mathrm{p}=.437)$, or household income $(r=-.028, \mathrm{p}=.403)$. The frequency of idle time was significantly negatively correlated with age $(r=-.072, p=.032)$ and education level $(r=-.079, p=0.020)$, but not household income $(r=-.002, p=.945)$. Although household income is not a perfect proxy for individual income, they are highly related; given that all participants were employed, they would either be the sole income earner or a contributing source to household income. It should also be noted that the significant correlations between frequency of idle time and age/education level 
were very small in size $(\mathrm{r}<0.10)$, and were likely only detected in part due to the large sample size.

The financial implications of this idle time are substantial. To estimate how much employers pay in wages for time employees spend idle, we use conservative assumptions. First, we assume that, on average, our survey respondents earned the median annual wage in the United States of \$17.09 per hour, which is significantly lower than the mean hourly wage of \$22.71 based on the U.S. Census ("May 2014 national occupational employment and wage estimates: United States," 2014). Assuming 50 weeks of work per year, we estimate the yearly wages for time spent idle to the people who took our survey to be $\$ 977$ [95\% CI (\$789, \$1166)] for each of the 1,003 workers, or approximately $\$ 980,000$ [95\% CI $(\$ 791,000, \$ 1,170,000)]$ in total - nearly one million dollars. Given that more than 135 million people are employed in the United States ("May 2014 national occupational employment," 2014) and that 95.7\% of those people work primarily outside the home (Mateyka \& Rapino, 2012), the findings from our study lead us to estimate that 7.4 billion hours of idle time are experienced by U.S. workers each year. Consequently, using this time estimate and the median U.S. wage (\$17.09), the estimated annual wages paid to employees for time spent idle would be over $\$ 100$ billion dollars.

The results from this nationally representative survey provide clear evidence that idle time at work is a frequent experience across diverse occupations in the United States, with substantial financial implications for firms and the economy overall. Further, because almost half of employees experience idle time on a weekly basis, with over $20 \%$ experiencing idle time daily, a substantial proportion of employees are likely in a frequent state of anticipating idle time. Thus, idle time is an economically and psychologically important phenomenon that deserves further empirical and theoretical exploration. 
It is important to note that the over $\$ 100$ billion estimate of wages paid to employees for time spent idle is unlikely to be a total loss; under certain circumstances, there can be ancillary benefits to idle time, such as being available for unexpected tasks or unexpected OCBs. However, in order for these benefits to be realized, employees would actually have to be available during possible idle time. Our subsequent studies (Studies 2a through 4) were designed to test whether workers' natural tendencies in reaction to anticipated idle time might undermine their availability. Specifically, we test whether there are collateral consequences of anticipated idle time for work pacing.

\section{STUDIES 2A \& 2B}

We began our examination of idle time by testing both Hypothesis 1, to investigate whether people slow down due to idle time, and Hypotheses $2 \mathrm{a}$ and $2 \mathrm{~b}$, to determine the manner in which people might slow down. Studies 2a and 2b specifically tested how the expectation of experiencing idle time after a task could impact work pacing. Study 2a utilized a design in which participants had a recent salient experience of idle time prior to the task of interest. To determine whether our results were generalizable to situations in which workers did not recently experience idle time, Study 2b utilized a similar design, but did not involve a recent salient experience of idle time. These situations are similar to that of an employee who may be assigned low time pressure tasks, and lacks the ability to begin new tasks to fill any remaining idle time. Studies 2a and $2 \mathrm{~b}$ were conducted sequentially, in a laboratory, and no participants in any of our Studies 2a4 participated in more than one study.

\section{Methods}

Participants. Participants in Studies 2a and 2b were, respectively, 47 and 60 undergraduate students studying in the United States, who passed a pre-screening survey for 
typing speed (Study 2a ${ }^{1}$ : 32 Female, $M_{\text {age }}=20.50, \mathrm{SD}=1.39$; Study $2 \mathrm{~b}$ : 33 Female; $\mathrm{M}_{\mathrm{age}}=22.63$, $\mathrm{SD}=5.08$ ). The purpose of this pre-screening survey was to ensure that all participants would have the capacity to complete the task within the allotted time.

Prescreening survey. The prescreening survey consisted of two questions to gauge typing speed to ensure that participants in our study would have idle time. The first question was "When using a computer do you: 1) generally only use a couple of fingers to type, 2) generally use most of your fingers to type, or 3) generally use all of your fingers to type?” The second question was “When using a computer do you: 1) need to look at the keyboard while typing, 2) sometimes need to look at the keyboard while typing, or 3) rarely or never need to look at the keyboard while typing?” In order to qualify for the study, participants needed a score of at least five on the survey (i.e., they either selected choice three for both questions, or choice two for one question and choice three for the other). Across Studies 2a-4, between $68 \%-72 \%$ of potential participants passed these screening questions.

Design and procedure. When participants entered the laboratory (at least 24 hours after the prescreening survey), they were given two envelopes marked “Task 1” and “Task 2,” and were told not to open the envelopes until they were instructed to do so. All participants were told to leave their personal belongings, including cell phones and books, in a separate room. The participants were then seated at private cubicles with a computer, where they were told that they would be completing two data entry tasks carrying a performance incentive of $\$ 2$ for completing the tasks with a limited error rate. The participants were not given any feedback regarding their error rates during the study. Participants were also informed that they would not be able to use the Internet at all during the study; Internet access was blocked on all computers.

\footnotetext{
${ }^{1}$ One participant's demographic information was not included in the analyses because the participant provided an incorrect code to match his or her pre-screening survey to his or her results.
} 
Task 1 was intended as a baseline task to serve two purposes: (1) to gather baseline completion time and error rate measures from participants to increase the power of our analyses, and (2) to familiarize participants with the duration of the task, thus inducing an expectation of idle time for a second, similar task. For Task 1, participants were instructed that they would be typing 46 sentences, listed on a paper inside one of the envelopes, into the computer. Participants in Study 2a were told that they would have 20 minutes to enter the sentences, and would not be able to move on to the next task until the entire 20 minutes had expired. Participants in Study $2 \mathrm{~b}$ were informed of the same deadline, but told that they could move on to the second task as soon as they were done (and did not need to wait for the time in the baseline task to expire). Additionally, participants were instructed that some of the sentences provided would contain intentional errors, and that they should copy the sentences exactly as they were written without correcting any of the errors (e.g., "the principel called all the students into the auditorium”). This task format was used because pilot testing indicated that it was complex enough to yield a nonzero error rate, and it was a task in which participants could improve their error rate through greater effort and concentration.

To avoid biasing error rates downward, spell check was disabled on all computers. Participants were able to enter one sentence at a time, and were required to click the "Next" button and proceed to a new screen (i.e., a new sentence) after entering each sentence. There was a 20-minute timer at the top of every screen, which counted down the remaining time.

In Task 1 of Study 2a, once participants entered the $46^{\text {th }}$ sentence, they were brought to a page with the text: "You may not begin the next task until the timer has reached zero. The 'next' button will appear at the bottom of the page, enabling you to move to the next task, when the entire twenty minutes have elapsed.” In Task 1 of Study 2b, all participants could move on to the 
second task as soon as they entered the $46^{\text {th }}$ sentence.

The independent variable, expected idle time, was manipulated in Task 2. After participants moved on from the first task, they were informed that they would be completing an identically formatted task with different sentences for Task 2. Task 2 was comparable in length to Task 1; both tasks contained 46 sentences, each with an average sentence length of 7.4 words. Participants were randomly informed either that they would have to wait for the entire 20 -minute timer to expire before moving on to the next section of the study, or that they would be able to move on to the next section at their discretion after completing the $46^{\text {th }}$ sentence. To allow clean tests of pacing changes within a task, this second task was designed such that there was a correlation of less than 0.1 between the character count in each sentence and the order in which the sentence appeared. Additionally, we controlled for character count in all pacing analyses. To ensure that all participants had the same externally set deadline, all participants in both conditions were told that they had 20 minutes to complete the task, and each condition had the 20-minute timer counting down across all of the task pages; the only difference was that those in the condition with expected idle time were told they had to wait for the timer to expire before moving forward in the study.

Studies 2a and 2b were approved by Harvard University’s Institutional Review Board, protocol number F22296 (Title: Predictable downtime and efficiency).

\section{Measures}

Sentence completion time. A timestamp was recorded each time a participant clicked “Next” after entering a sentence. The time spent on each of the 46 sentences in Task 2 was used as our primary measure of work pace.

Error rate. Given that there were a variety of ways that errors could be tabulated (e.g., 
skipping a six-letter word in a sentence could be counted as one error or six errors, one for each incorrect letter), we used the more straightforward measure of whether a sentence was completely correct or not.

\section{Results and Discussion}

Studies 2a-4 utilized a similar methodology, so we made uniform data analysis decisions across all studies. Across Studies 2a-4, a very small percentage of participants spent very long periods of time waiting during a single sentence. Across the five studies, in Task 2, the primary task of interest, only between $0 \%$ and $0.006 \%$ of sentence times in each study were above 60 seconds. Thus, because these few outlier sentences exerted a disproportionate amount of leverage on the data, we decided to remove any sentence times for which a participant spent more than 60 seconds $^{2}$. Even if a participant had a sentence time removed for this reason, we still retained all of his or her other sentences.

The sample sizes, mean sentence times, and participant error rates (number of incorrect sentences out of 46 sentences) for Task 2, separated by condition for Studies 2a-4, appear in Table 1. Across all studies, participants finished the first task in 10-12 minutes, on average, leaving 8-10 minutes - ample potential idle time - prior to the 20-minute deadline. Given that mean error rates in all studies were four times larger than the standard error, there was no evidence of a floor effect in terms of error rate.

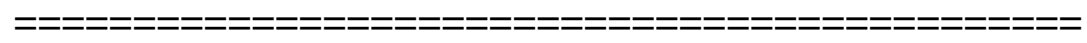

\section{Insert Table 1 Here}

\footnotetext{
${ }^{2}$ These sentences were removed because: a) these sentences were primarily in the idle time condition (72\% of such sentences were from the idle time condition), which would have biased the results in favor of Hypothesis 1 ; b) these sentences were primarily toward the end of the task ( $54 \%$ of the dropped sentences were in the final 10 out of 46 sentences of the task), which would have biased the results in favor of Hypotheses 2a and 2b; and c) a few of these sentences had massive amounts of leverage within their samples (over 50 standard deviations above the mean), which would have caused our results to be driven by these extreme outliers rather than by general trends across participants.
} 


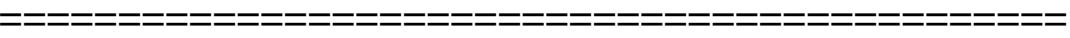

Our main dependent variable was the amount of time participants spent completing each sentence in Task 2. To test whether those in the idle time condition took longer to complete the task than those in the control (no idle time) condition (Hypothesis 1), and to examine the dynamics of their pacing throughout the task (Hypotheses 2a and 2b), we used hierarchical linear modeling within HLM 7.01, with full information maximum likelihood estimation, to account for the nested nature of the data (Bliese \& Ployhart, 2002).

To determine whether (Hypothesis 2a) and how (Hypothesis 2b) individuals altered their work pace throughout the task, we created orthogonal polynomials for both a linear term and a squared term for the sentence number (i.e., sentences 1-46 within the task). Orthogonal polynomials were utilized because they eliminate the multicollinearity associated with normal polynomial terms (Draper, Smith, \& Pownell, 1966; Kleinbaum, Kupper, Nizam, \& Rosenberg, 2013; Ployhart \& Vandenberg, 2010). The values for the orthogonal polynomials were calculated using the 'poly' function in R (R Core Team, 2014). The linear term was included to determine whether sentence completion times increased linearly for participants in the idle-time condition as they progressed through the task (the simplest test of Hypothesis 2a). The squared term was included to determine whether participants in the idle time condition slowed down at an increasing rate (i.e., non-linearly) throughout the task, as would be expected if the main effects were, in fact, driven by time discounting (Hypothesis 2b). We used the orthogonal polynomial terms for sentence number as Level 1 predictors, and interacted the Level 1 orthogonal polynomial terms with the two Level 2 predictors (the experimental condition and baseline typing speed) to test differences in slopes between conditions. Given that both initial rates and trends of work pacing are likely to vary by individual, we allowed these intercepts and slopes to 
randomly vary.

We dummy coded the idle time condition as 0 , and the no idle time condition as 1 . Doing so allowed us to interpret the Level 1 coefficients for Sentence Number $\left(\gamma_{10}\right)$ and Sentence $\operatorname{Number}^{2}\left(\gamma_{11}\right)$ as indicators of whether the idle time condition slowed down linearly and/or quadratically, respectively, throughout the task. (The Level 1 coefficients are the effects, often referred to as intercepts, when condition $=0-$ which in this case, equates to those participants who expected idle time.) The Level 2 coefficients for Condition x Sentence Number $\left(\gamma_{11}\right)$ and Condition $x$ Sentence Number $^{2}\left(\gamma_{21}\right)$ indicate whether the idle time condition slowed down linearly and/or quadratically, respectively, relative to the control (no idle time condition) (i.e., differences in slopes between the two conditions). Accordingly, this model involved two types of pacing pattern tests, examining: a) whether and how the idle time condition slowed down absolutely (Level 1 Coefficients $\gamma_{10}$ and $\gamma_{11}$ ); and b) whether and how the idle time condition slowed down relative to the no idle time condition (Level 2 Coefficients $\gamma_{11}$ and $\gamma_{21}$ ). The grandmean centered baseline time (mean sentence time from Task 1) and the dummy code for the experimental condition were used as Level 2 predictors (Hofmann \& Gavin, 1998). To eliminate any trends due to some sentences being longer than others, we controlled for sentence character count (grand-mean centered) on Level 1. The equations, results of this analysis, and comparable analyses for Studies 2a-4, are shown in Table 2.

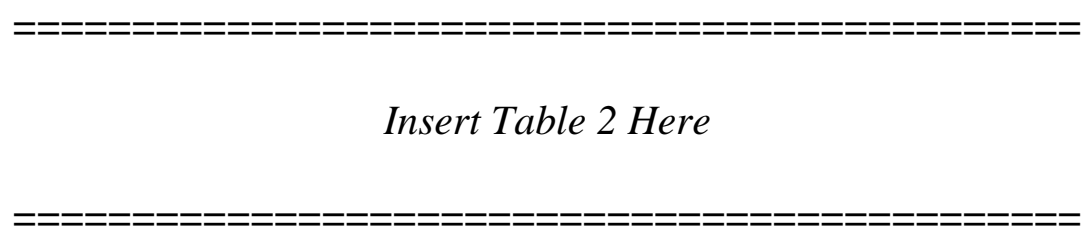

In both Studies 2a and 2b, we found that participants in the idle time condition took significantly more time to complete the second task than those in the no idle time condition 
[Study 2a: $\gamma_{01}=-1.720, \mathrm{t}(44)=-3.501, \mathrm{p}=.001$; Study $\left.2 \mathrm{~b}: \gamma_{01}=-1.044, \mathrm{t}(57)=-2.162, \mathrm{p}=.035\right]$. When comparing the mean sentence times by condition for Task 2 [( mean $_{\text {idle time-mean }}$ no idle

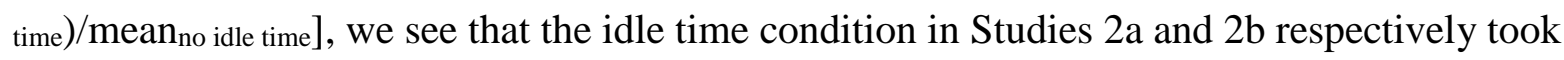
$7.6 \%$ and $21.3 \%$ more time to complete the task than the no idle time condition. These findings support Hypothesis 1: idle time leads to a longer task completion time.

In both studies, sentence completion times in the idle time condition increased as participants progressed through the task [Study $2 \mathrm{a}: \gamma 10=20.272, \mathrm{t}(44)=2.033, \mathrm{p}=0.048$; Study 2b: $\gamma 10=24.379, \mathrm{t}(57)=2.717, \mathrm{p}=0.009]$, indicating that participants slowed down as idle time approached. Furthermore, the linear effect of sentence number was stronger in the idle time condition than the no idle time condition [Study $2 \mathrm{a}: \gamma 11=-31.688, \mathrm{t}(44)=-2.355, \mathrm{p}=0.023$; Study $2 \mathrm{~b}: \gamma 11=-27.110, \mathrm{t}(57)=-2.105, \mathrm{p}=0.040]$, indicating that the extent of slowing was greater in the idle time condition than in the no idle time condition. It is important to consider these effects in tandem, as the former effect indicates whether participants slowed down absolutely, and the latter effect (the interactive effect between conditions) eliminates any confounding mechanisms that may be associated with the task itself. For instance, because we know that the idle time condition slowed down to a greater degree than the no idle time condition, we can be more certain that the effect was driven by the expected idle time rather than simply energy depletion, which would have had an equal impact in both conditions. These findings support Hypothesis 2a; participants slowed down as the task progressed (and idle time approached).

In Study 2a, we did not find either a significant quadratic change in pace for the idle time condition $\left[\gamma_{20}=0.182, \mathrm{t}(44)=0.029, \mathrm{p}=0.977\right]$, or a difference in slopes for this effect between conditions $\left[\gamma_{21}=-5.320, t(44)=-0.648, p=0.520\right]$. In Study $2 b$, although the quadratic effect for 
the idle time condition was trending in the predicted direction, it was not significant $[\gamma 20=9.966$, $t(57)=1.369, p=0.176]$. However, there was a significant difference in slopes for this effect between conditions $\left[\gamma_{21}=-33.356, t(57)=-3.252, p=0.002\right]$. Although these findings do not provide clear support for Hypothesis 2b, that workers expecting idle time will slow their work pace at an increasing rate as the task progresses, they indicate that a more highly powered study design may be necessary to determine the existence (or non-existence) of this effect.

Taken together, these results indicate a general deadtime effect, whereby idle time seemed to have exerted more influence on participants’ behavior as it approached. The significant linear terms indicated that participants in the idle time condition slowed down as the idle time drew nearer (Hypothesis 2a). However, the non-linear effect predicted by Hypothesis 2b, which would have more convincingly pointed to time discounting as the underlying mechanism, was not significant. We graph the pacing results for both studies in Figure $2^{3}$.

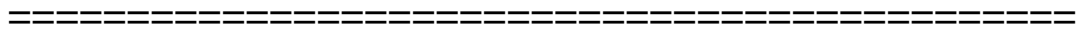

Insert Figure 2 Here

Lastly, we conducted a regression analysis to determine if error rate varied by condition, with condition predicting error rate in Task 2, controlling for the Task 1 baseline error rate. To maintain consistency with our multilevel model, the idle time condition was coded as 0 and the no idle time condition was coded as 1 . As can be seen in Table 3, there were no significant differences in either study between conditions for error rates in Task 2 . The only reliable predictor of participants’ error rate in Task 2 was their error rate in Task 1.

\footnotetext{
${ }^{3}$ For ease of interpretation, in all pacing figures, we display the actual sentence numbers on the $\mathrm{X}$ axis of the figure even though these numbers were transformed to orthogonal polynomial terms for the analyses. This decision does not alter the shape of the curve in any manner, only the labels on the $\mathrm{X}$ axis.
} 


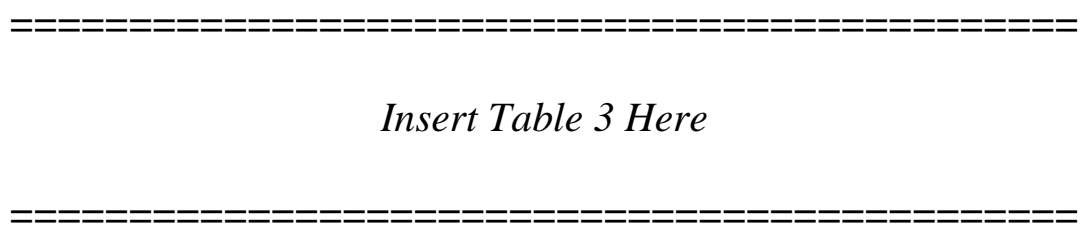

The results of Study 2a and 2b provide replicated evidence that, when given more than enough time for a task, people who are unable to avoid idle time not only work more slowly than those able to avoid idle time, but also slow down progressively as idle time draws nearer. Moreover, participants slowed down without a detectable improvement in error rates. As a result, this change in pace appears to be a pure loss. Further, Study $2 \mathrm{~b}$ shows that this effect is robust regardless of whether participants had a recent salient experience of idle time.

Although the work pacing results support our predictions of work-stretching, Studies 2a and $2 \mathrm{~b}$ provide only partial evidence for the proposed mechanism of time discounting. Although there was a significant difference in the quadratic effect between conditions in Study 2b, there was no absolute quadratic effect for the idle time condition. Given that there was some evidence of time discounting in Study 2, and given that the quadratic effects for the idle time conditions in both Studies 2a and 2b trended in the predicted direction, it is plausible that a non-linear effect does exist, but that our studies were underpowered due to the low sample sizes ( $n=47$ and $n=60)$ that could be collected in a laboratory with a very limited subject pool. Consequently, to provide more robust tests of Hypotheses 1, 2a, and 2b, we undertook replication of these studies using larger online samples in Studies 3a and 3b.

\section{STUDIES 3A \& 3B}

To replicate Studies 2a and 2b with greater power, Studies 3a and 3b employed a design and procedure nearly identical to those of Studies 2a and 2b, respectively. However, we made a few minor changes to render the procedure more suitable for an online subject pool, which would 
allow us access to a much larger number of potential participants. Because online platforms generally offer shorter studies, we cut the number of sentences and time in the baseline task, Task 1, in half (to 23 sentences and 10 minutes). However, the number of sentences and time in Task 2 remained identical to those in the prior studies (46 sentences and 20 minutes). The only difference between Studies 3a and 3b was that participants in Study 3a were forced to experience idle time in Task 1 (the baseline task, as in Study 2a), and participants in Study 3b were able to move on from Task 1 as soon as they completed it (as in Study 2b). Conducting the two separate studies with differing designs allowed us to ensure both that our results were generalizable to situations where workers may or may not have recently experienced idle time, and that our results were replicable.

Additionally, because participants were not physically present in the lab, we needed a method to ensure that they expected the idle time to be truly idle. Thus, we told participants that they must not leave the study or engage in any other activities during idle time. We stressed that if they were found to have left the survey screen or be inactive for more than 30 seconds, they might be removed from the study. To strengthen these restrictions, we used the following instructions for the segments of the study where idle time was expected (Task 1 for all participants in Study 3a, and Task 2 for participants in the idle time conditions in both Studies 3a and 3b): "For this task, you will not be able to move to the next section until the entire 10 [20]minute timer has expired. If you finish the task early, while you are waiting for the 10 [20]minute timer to expire, you will be asked to click on a button once every 20 seconds to indicate that you are still active and not doing other work.” By forcing participants to click a button to indicate that they were still present in the study every 20 seconds, we ensured that they were 
severely restricted from being able to engage in any other activities during the idle time ${ }^{4}$.

Lastly, as online study participants sometimes engage in cross-talk on forums, we employed two methods to ensure that the details of the typing-ability selection criteria and the study manipulation were not shared: (1) the selection criteria were embedded with other irrelevant questions to mask which ones were study-relevant, and (2) we actively monitored the popular Amazon Turk online forums (e.g., Reddit and MTurkforum) for discussion of the nonadvertised details of our studies; we found none posted.

Studies 3a and 3b were approved by Harvard University’s Institutional Review Board, protocol numbers IRB15-2238 (Title: Idle Time Study) and IRB15-2238 (Title: Idle Time Study).

Participants. Participants in Studies 3a and 3b were, respectively, 397 and 400 workers on Amazon Mechanical Turk in the United States who passed the initial prescreening survey and a set of attention filters (Study 3a: 193 Female; $M_{\text {age }}=33.90, \mathrm{SD}=10.98$; Study 3b: 221 Female; $\left.\mathrm{M}_{\mathrm{age}}=35.96, \mathrm{SD}=9.93\right)$.

\section{Results and Discussion}

We conducted analyses identical to those in Studies 2a and 2b to examine work pacing and error rates. Given that the model structures in Studies 3a and 3b are identical to those of Study 2a, the coefficients in Table 2 can be interpreted as previously described in Study 2a. In both studies, we found that participants in the idle time condition took significantly more time to complete the second task than those in the no idle time condition [Study 3a: $\gamma_{01}=-1.572, \mathrm{t}(394)=$

\footnotetext{
${ }^{4}$ If participants did not click the "Next" button within the given time frame, they were still included in the study to avoid biasing our data by only removing participants who had idle time. This was a conservative test, as participants who were not planning on being idle during idle time would have been less impacted by our manipulation.
} 
-7.164, $\mathrm{p}<0.001$; Study 3b: $\left.\gamma_{01}=-0.931, \mathrm{t}(397)=-5.550, \mathrm{p}<0.001\right]$. When comparing the mean sentence times by condition for Task 2, the idle time conditions in Studies 3a and 3b took respectively $14.7 \%$ and $12.3 \%$ longer to complete the task than the no idle time condition. These findings support Hypothesis 1; idle time leads to longer work completion times. In support of Hypothesis 2a, we again observed, in both studies, that sentence completion times in the idle time condition increased as participants progressed through the task [Study 3a: $\gamma_{10}=98.097$, $\mathrm{t}(394)=8.069, \mathrm{p}<0.001$; Study 3b: $\left.\gamma_{10}=90.505, \mathrm{t}(397)=8.842, \mathrm{p}<0.001\right]$, and the linear effect of sentence number was stronger in the idle time condition than the no idle time condition [Study 3a: $\gamma_{11}=-45.860, \mathrm{t}(394)=-2.610, \mathrm{p}=0.009$; Study 3b: $\left.\gamma_{11}=-47.755, \mathrm{t}(397)=-3.393, \mathrm{p}<0.001\right]$. Together, these results reveal that participants in the idle time condition slowed down significantly as the task progressed.

With the increased sample size in both studies, we did observe a significant acceleration in the degree of slowing down (a quadratic effect) for the idle time condition as participants progressed throughout the task [Study 3a: $\gamma_{20}=53.490, \mathrm{t}(394)=6.281, \mathrm{p}<0.001$; Study 3b: $\gamma_{20}=$ 38.843, $\mathrm{t}(397)=4.682, \mathrm{p}<0.001]$. Moreover, the slope of this effect was significantly different between conditions [Study 3a: $\gamma_{21}=-43.686, \mathrm{t}(394)=-3.609, \mathrm{p}<0.001$; Study 3b: -26.547 , $t(397)=-2.364, p=0.019]$. These replicated findings strongly indicated that participants in the idle time condition slowed down non-linearly, providing evidence of time discounting as the underlying mechanism for participants’ behavior (Hypothesis 2b). We graph the pacing results for these studies in Figure 3.

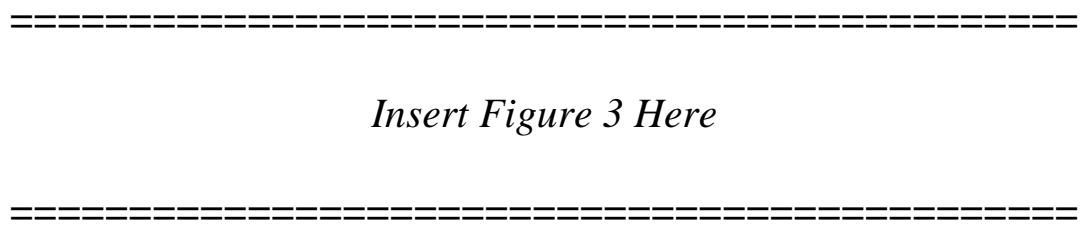


As shown in Table 3, there were, once again, no detectable differences between conditions in the number of errors made in Task 2 for both studies.

Studies 2a, 2b, 3a, and 3b provide strong, replicated evidence that task completion time increases under expected idle time (Hypothesis 1). Moreover, these studies provide replicated evidence of the deadtime effect, whereby participants slow down as idle time becomes more proximate (Hypothesis 2a). The two more highly powered studies, Studies 3a and 3b, provided replicated evidence that participants slow down non-linearly as idle time approaches (Hypothesis 2b), which strongly suggests time discounting as the underlying mechanism. Moreover, in none of the four studies (2a-3b) was there any significantly detectable error rate difference between conditions. In light of the fact that two of our studies involved sample sizes of approximately 200 participants per condition, our findings suggest that even if there were any error rate differences due to expected idle time in these studies, the effect would likely be extremely small relative to the effect of expected idle time on task completion time.

\section{STUDY 4}

Studies 3a and 3b offered consistent evidence supporting our proposed mechanism for the deadtime effect: time discounting of the future aversive experience of idle time. We designed Study 4 to achieve dual aims. One was to examine this proposed mechanism in quite a different way, by increasing the attractiveness (and reducing the aversiveness) of idle time and, thus, attempting to reduce or eliminate the deadtime effect (Hypothesis 3). The second aim was a practical one. Because idle time may be unavoidable in many jobs, it would be desirable to fill potential idle time, rendering it less "dead" and, thus, reducing the work stretching that arises from expected idle time. Allowing employees to engage in leisure activities during downtime, specifically by accessing the Internet, offers one possibility for doing so. 
Given the need to control participants' Internet access, we conducted Study 4 in the laboratory. For all participants, we used a procedure similar to that of the idle time condition in Studies 2b and 3b: participants were able to move on at will in Task 1, but had idle time in Task 2. The only difference was that, at the beginning of the second task, half of the participants were informed that they would be able to use the Internet after completing the task. Additionally, instead of the 20-minute deadline and timer used in the previous experiments, a 25-minute deadline and timer were used for both tasks in this study to ensure that there would be ample time for participants to use the Internet.

This study was approved by Harvard University's Institutional Review Board, protocol number F22937 (Title: Predictable downtime and efficiency - study 3).

Participants. Participants were 107 full time undergraduate and graduate students studying in the United States who passed the typing prescreening survey (68 Female; $\mathrm{M}_{\mathrm{age}}=$ 22.15, $\mathrm{SD}=5.41)^{5}$.

\section{Results and Discussion}

We conducted analyses identical to those in Studies 2a-3b to examine work pacing and error rates. Given that the model structure in Study 4 is identical to that of Study 2a, the coefficients in Table 2 can be interpreted as described in Study 2a. We found that participants in the empty idle time condition took significantly more time to complete the second task than those in the Internet condition $\left[\gamma_{01}=-0.801, \mathrm{t}(104)=-2.481, \mathrm{p}=0.015\right]$. When comparing the mean sentence times by condition for Task 2, we see that the idle time condition took 9.1\% longer to complete the task than the no idle time condition. These findings support Hypothesis 1; idle time leads to longer task completion times. We again observed that sentence completion

\footnotetext{
${ }^{5}$ We eliminated all data from one participant who entered random letters instead of the sentences.
} 
times in the idle time condition increased (both absolutely and relative to the no idle time condition) as participants progressed through the task $\left[\gamma_{10}=22.778, \mathrm{t}(104)=2.990, \mathrm{p}=0.003 ; \gamma_{11}=\right.$ -21.937, $\mathrm{t}(104)=-2.100, \mathrm{p}=0.038]$, further supporting Hypothesis 2a. However, we did not observe either a significant quadratic slowing down effect for the idle time condition $\left[\gamma_{20}=\right.$ 3.448, $\mathrm{t}(104)=-0.460, \mathrm{p}=0.646]$ or a difference in slopes for this effect between conditions $\left[\gamma_{21}=\right.$ $-1.661, \mathrm{t}(104)=-0.164, \mathrm{p}=0.870]$. We graph the pacing results in Figure 4 . Lastly, as shown in the Study 4 results for Table 3, there were, as in all other studies, no detectable differences between conditions in the number of errors made in Task 2.

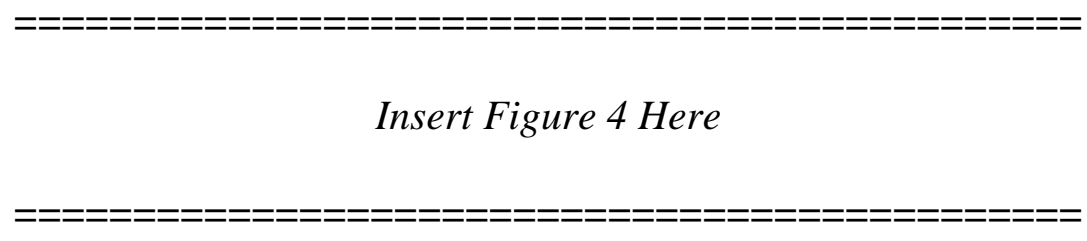

Study 4 did not provide evidence of a significant non-linear trend (Hypothesis 2b), failing to replicate this specific result from Studies 3a and 3b. This is not entirely surprising, given that we were restricted to the smaller sample size of participants who could be recruited to the laboratory. However, there may be a more substantive explanation for this non-replication. Given that Studies 3a and 3b (where the quadratic effect was detected) were conducted online, but the other studies (2a, 2b, and 4) were conducted in the laboratory, it is plausible that a context-based moderator exists that could influence whether participants will slow down nonlinearly. We believe the most likely phenomenon-relevant difference between these two study contexts is that participants in the laboratory were being monitored by a researcher who was physically present to answer questions throughout the session; moreover, participants may have additionally believed that they were being monitored by video cameras mounted at participants' work stations (which are built-in but were not utilized in this study). By contrast, online 
participants were able to work from the comfort of their homes, with no visual monitoring.

Workers who are being monitored are likely to feel less comfortable slowing down to as great an extent as workers who are not being monitored, and a higher degree of slowing down is required to detect any non-linear effects. In other words, the highest degree of slowing down when idle time draws very near, which drives the non-linear effect, may have been censored in the lab studies because workers were uncomfortable slowing down beyond a certain level.

Our data provide some support for this speculation. By separately averaging the laboratory (Studies 2a, 2b, and 4) and online (Studies 3a and 3b) sentence \#1 and sentence \#46 completion times for the idle time condition as predicted by the studies' multilevel models, we observed that both contexts had similar sentence \#1 times [Mean ${ }_{\text {Lab }}=14.63$; Meanonline= 14.96; Difference $=0.33]$. However, the difference between the laboratory and online models’ predicted sentence \#46 times was 1.32 seconds [Mean ${ }_{\mathrm{Lab}}=16.02$; Mean Online $\left.=17.34\right]$. This difference is quite substantial, considering that the models predict the participants in the lab studies to slow down a total of 1.39 seconds from sentence \#1 to sentence \#46. In other words, it appears that context may alter the degree to which those in the idle time conditions slow down.

The results of this study support Hypothesis 3 by showing that the availability of leisure activities can reduce the negative pacing effects of expected idle time, without significantly detectable alterations in error rates. These results further bolster the argument that the reason that participants engage in work-stretching in the face of expected idle time is that they seek to avoid an aversive period of time. When idle time is rendered less aversive, participants are less eager to avoid it.

\section{GENERAL DISCUSSION}

Taken together, our studies offer evidence that idle time at work is broadly prevalent and 
highly consequential for employees and organizations. Study 1 revealed that the vast majority of workers across a broad array of job categories experience idle time at least occasionally, and allowed us to quantify the phenomenon with an estimate of $\$ 100+$ billion paid annually to employees for time spent idle. Although it is likely that a large portion of this idle time is a pure loss due to organizational inefficiencies, a significant portion may be rationally planned and valuable to organizations as slack that can increase innovation and enable employees to better meet unexpected demands (Amabile et al., 2002; Pfeffer \& Salancik, 1978; Woodman, Sawyer, \& Griffin, 1993). However, Studies 2a-4 show that the goal of having employees available during idle time may be counteracted by work-stretching: workers' natural tendency is to stretch out their work unproductively, without a noticeable improvement in error rates, when they anticipate empty idle time after task completion. Moreover, these studies suggest that the deadtime effect is driven by time discounting: as idle time draws closer, it exerts a non-linear, accelerating negative impact on worker task completion speed.

\section{Theoretical Contributions}

Our studies contribute to multiple components of theory on work. Prior theory on work pacing, though illuminating, is narrow in several respects. Perhaps most importantly, by primarily explicating pacing patterns that involve speeding up in response to tight deadlines

(Gersick, 1989; Lim \& Murnighan, 1994; Waller et al., 2002), pacing theory can only explain a limited subset of work pacing behavior. By exploring workers' behavioral responses to anticipated idle time, we introduce a new type of highly consequential pacing behavior into the literature: the deadtime effect.

Moreover, consistent results from Studies 3a and 3b allowed us to theorize about the psychological mechanism underlying the deadtime effect. The work pacing patterns in those 
studies suggested that participants engaged in a type of time discounting (Critchfield \& Kollins, 2001; Samuelson, 1937; Steel \& König, 2006), whereby expected idle time had limited influence over their work behavior when it was distant, but, as it approached, it had an increasing impact on their task completion times. It appears that participants sought to avoid the aversive experience of having nothing to do after task completion. The results of Study 4 furthered this theoretical argument and also provided a potential tool for mitigating some of the costs of expected idle time; when idle time was rendered less aversive by access to a leisure activity (Internet access), participants decreased the degree to which they avoided idle time through work-stretching.

Previous research has focused on pacing problems during the early stages of a task, such as procrastination in beginning a task or working slowly until a deadline is imminent (Lay, 1986; O'Donoghue \& Rabin, 1999; Steel, 2007). This focus has led to an implicit assumption that work pace is either constant or highest toward the ends of tasks, as workers speed up to meet deadlines. Accordingly, most theory on pacing has concentrated on how and why behavioral interventions might alter pacing at the beginning of work tasks, when work pace is assumed to be slower; this includes interventions such as structured team launches and methods for overcoming initial procrastination (Hackman \& Wageman, 2005; Steel, 2007). Evidence of the deadtime effect suggests that, in order to develop comprehensive theory on work pacing, it is also important to conceptualize and test interventions that can affect work pace near the end of tasks.

As demonstrated in our studies, one such intervention addresses workers' expectations about how time will be spent following a task with an excessively distant deadline - specifically, their expectations about whether that time will be spent completely idle, busy with additional work, or engaging in leisure activities. Prior theory on work pacing has principally focused on 
how characteristics of the task period itself, such as the nature of the work and task deadlines (Gersick, 1988; Waller et al., 2002), alter employee productivity. We provide evidence that expectations of how time will be spent following a task can alter work behavior dramatically. The deadtime effect revealed in Studies 2a through 4 is a complete reversal of the deadline effect; rather than speeding up, people who expect empty idle time following a task slow down as the deadline draws near.

Because idle time is likely only one type of anticipated work time that may lead to workstretching, the theoretical implications of our findings extend beyond idle time. For instance, if workers were to face an undesirable subsequent task, such as making cold calls or dealing with a customer complaint, they might slow down on a current task to postpone or reduce the amount of time available for the undesirable task. Such effects could extend even beyond the confines of the work day. It is possible that if an employee’s planned after-work activities are perceived as undesirable (e.g., paying bills or house cleaning), that employee may work very slowly during the day and extend her work well beyond normal work hours. All of these behaviors could be highly problematic for organizations because, by stretching out their work, employees are less available for any unexpected tasks or organizational citizenship opportunities that may arise (Hui et al., 1994; Pfeffer \& Salancik, 1978; Woodman et al., 1993).

Lastly, in theorizing about the design of work, many scholars and managers focus on job design, the ways in which specific work tasks can be altered to improve motivation and productivity. Recently, a new focus has emerged, expanding to the design of the workday as a whole - specifically, the ways in which different work tasks might combine to form the overall workday experience. For instance, based on considerable prior empirical evidence, Elsbach and Hargadon (2006) theorize that when there is significant workload pressure, interspersing 
cognitively demanding tasks with relatively mindless ones can enhance employee creativity and motivation. Our research broadens the conceptualization of workday design by showing that it is valuable to consider not only the work tasks that comprise a workday, but also all of the time including idle time - that may come between and after those tasks.

\section{Limitations and Future Directions}

Study 1 provides strong evidence of the widespread prevalence of idle time across occupations. However, as with any self-report measures based on a sample of the population, our measures of the preponderance of idle time should be taken as estimates rather than statistics that are exactly representative of the population. Nevertheless, obtaining more accurate measures could be difficult. Although it would be ideal to capture objective measures of idle time as recorded by companies, it is probable that much of this information, if available, would be inaccurate. The work-stretching findings from Studies 2a-4 indicate that employees are likely to mask their true amount of idle time by working more slowly. One future alternative for gauging the quantity and consequences of idle time would be to use experience sampling. In an example of such sampling, previous researchers utilized iPhone applications to capture participants’ realtime experiences of mind wandering throughout the day (Killingsworth \& Gilbert, 2010).

The main results of Studies 2a-3b are replicated and robust; however, they are limited to the context in which they were obtained. Like past studies on work pacing (Gersick, 1989; Lim \& Murnighan, 1994), we chose to test our hypotheses in laboratory and online contexts. This choice followed from our need for precise measurements of both participant pacing and error rates, as well as the need for high control over the structure of participants’ work tasks and work time. As a result, we only tested the impact of a few minutes of expected idle time on behavior in a controlled setting. This design limits the external validity of these findings and their 
generalizability to other settings. For instance, in some real work contexts, it is plausible that the impact of expected idle time may be even more severe, given the potential negative consequences that may result when a manager observes a subordinate being idle (Chinander \& Schweitzer, 2003). It is also possible that idle time before a period of high time pressure work, such as restaurant servers having a short period of idle time before the dinner crowd surge, could actually be perceived as a positive occurrence - a welcome breather - which would provide an incentive for working quickly in the previous time period.

Further, potential error rate reductions due to work-stretching may have been masked in our studies by the selection criteria we used, because workers who typed very slowly (the bottom one-fourth to one-third) were excluded from our study to ensure that participants had ample idle time. Most organizations, like our study, seek to avoid hiring, or fire, the slowest workers. However, in situations where this does not hold true (e.g., for newly hired, untrained workers), it could be beneficial to force such lower-productivity workers to spend more time on a task. Additionally, our studies involved a situation in which idle time was almost guaranteed, to ensure that workers anticipated idle time. In some real work contexts, the anticipation of idle time may be just as certain, such as for a parking lot attendant working on a late Tuesday night. In other work contexts, the expectation of idle time may be high, but there may be less certainty about exactly when it will occur. From our findings, it is not fully clear if expected idle time functions similarly when its exact timing is less predictable. There is significant value in future studies exploring idle time across a range of conditions and contexts.

In addition to time discounting of a future aversive period of time, it is possible that other mechanisms may also underlie the deadtime effect. For instance, at the beginning of a low time pressure task, workers may underestimate the possible gap between the task they have to do and 
the amount of time they have to do it; as they get closer to the deadline, their estimate may become more accurate. Similarly, it is plausible that, as workers realize they have more time available, they become more attentive to their performance and slow down accordingly (even if this increased attention doesn’t necessarily improve performance). Only through more extensive testing of the mechanisms behind the deadtime effect—using different constructs, measures, and settings — will a full picture emerge as to exactly how anticipated idle time alters behavior.

Lastly, although we have provided initial evidence of the prevalence and consequences of idle time, there are still many aspects of this phenomenon that remain to be explored - aspects that may have significant implications for both management scholarship and organizational practice. For example, in examining the collateral costs of idle time, we focused on the costs of anticipated idle time, with little attention to the consequences of experienced idle time - that is, what happens to workers' affective states and work pacing during and following experienced idle time. It seems equally plausible that the consequences of experienced idle time could be positive (e.g., stress reduction and incubation of creative ideas) or negative (e.g., boredom and annoyance).

\section{Practical Implications}

This research provides evidence for a frequently experienced, yet largely ignored, phenomenon that commonly occurs in the work place: employees don't always have enough work to do. Consider in tandem two of our findings. Study 1 allows us to estimate that $21.7 \%$ of full-time workers in the United States experience idle time on a daily basis, likely leading them to frequently expect idle time. Studies 2a-3b show that, in the context of our studies, an average work completion time loss of $14.0 \%$ resulted from expected idle time. Thus, the negative consequences of excessive worker idle time for organizations are potentially severe. 
Unfortunately, it is likely that managers are not aware of the true extent of employee idle time (Malachowski, 2005) because it is in employees’ best interest to mask it (Chinander \& Schweitzer, 2003). Ideally, our research will, most fundamentally, call attention to the issue so that solutions can be developed.

Study 4 suggests a rather counterintuitive method for improving work completion time and consequent employee availability in cases of expected idle time: offering and legitimizing access to leisure activities during idle time. Our findings from Study 4 counter a widely-held assumption that allowing Internet access at work can only hurt employee productivity (Askew et al., 2014; Connor, 2013; Lim, 2002), and suggest a different approach in those companies currently restricting Internet access. However, managers should exercise caution when increasing employees’ ability to independently initiate leisure activities, to ensure that such secondary activities do not result in procrastination or interruptions of available work (Cottrell, Wack, Sekerak, \& Rittle, 1968; Jett \& George, 2003). To avoid these negative outcomes, one potential option would be to establish clear guidelines regarding the importance and order of activities. Another way to prevent secondary activities from interfering with primary tasks is to make engaging in leisure activities permissible during free time in a public space - for example, by providing access to games in a break room. Increased visibility of employees engaging in leisure activities could discourage the use of such activities when there are primary work tasks available.

Finally, if organizations were to openly acknowledge and sanction idle time as an unavoidable part of the work, for which employees would not be evaluated negatively, then the stigma associated with being idle could be reduced (Chinander \& Schweitzer, 2003; Elsbach et al., 2010). Consequently, if employees are more open about their idle time, managers will be able to better allocate work tasks. Also, instead of needing to hide idle time, employees could use this 
time to engage in various types of leisure, such as relaxing or socializing with colleagues who also have idle time - both of which yield secondary benefits to employee wellbeing and performance (Carlson \& Perrewé, 1999; Jett \& George, 2003; Seers, McGee, Serey, \& Graen, 1983). Taking this step of acknowledging the unavoidable presence of idle time could help make idle time feel more like_-and actually become_-a desirable work break.

\section{Conclusion}

From a theoretical and practical perspective, focusing only on the aspects of jobs that involve actually doing work neglects a substantial part of the job experience. To help managers optimize worker productivity and satisfaction, scholars should strive to develop a more comprehensive understanding of the experience of time at work. The amount of idle time and the activities in which employees can engage during idle time have considerable ramifications for employee performance, employees themselves, and entire organizations. 
Table 1. Summary Statistics for Studies 2a-4, Task 2.

DV

\begin{tabular}{|cccc|}
\hline \multirow{2}{*}{ Study 2a } & Mean Sentence Time & $13.71(0.15)$ & $14.75(0.17)$ \\
& Error Rate & $5.42(1.01)$ & $5.29(1.14)$ \\
& $\mathrm{n}$ & 26 & 21 \\
\hline \multirow{3}{*}{ Study 2b } & Mean Sentence Time & $13.55(0.15)$ & $16.43(0.18)$ \\
& Error Rate & $5.86(0.85)$ & $6.97(1.49)$ \\
& $\mathrm{n}$ & 30 & 30 \\
Study 3a & Mean Sentence Time & $13.72(0.07)$ & $15.74(0.07)$ \\
& Error Rate & $4.22(0.32)$ & $4.69(0.32)$ \\
Study 3b & $\mathrm{n}$ & 190 & 207 \\
& Mean Sentence Time & $14.00(0.06)$ & $15.72(0.08)$ \\
\hline \multirow{2}{*}{ Study 4 } & Mean Sentence Time & $6.30(0.36)$ & $6.19(0.40)$ \\
& Error Rate & 212 & 188 \\
\hline
\end{tabular}

Note. This table displays the means and standard errors (in parentheses) for the two primary measures in Task 2 (the task where the independent variable was manipulated) across Studies 2a-4. Given that the nature of the manipulations for the experimental conditions varied across studies, we refer here to the condition where we hypothesized observing the deadtime effect as the "Idle Time Condition." In Studies 2a, 2b, 3a, and 3b the "Idle Time Condition” is the idle time condition, and in Study 4 it is the empty idle time condition (no Internet access). 
Table 2.

Studies 2a-4: Results of Multilevel Modeling Analysis Predicting Sentence Completion Time

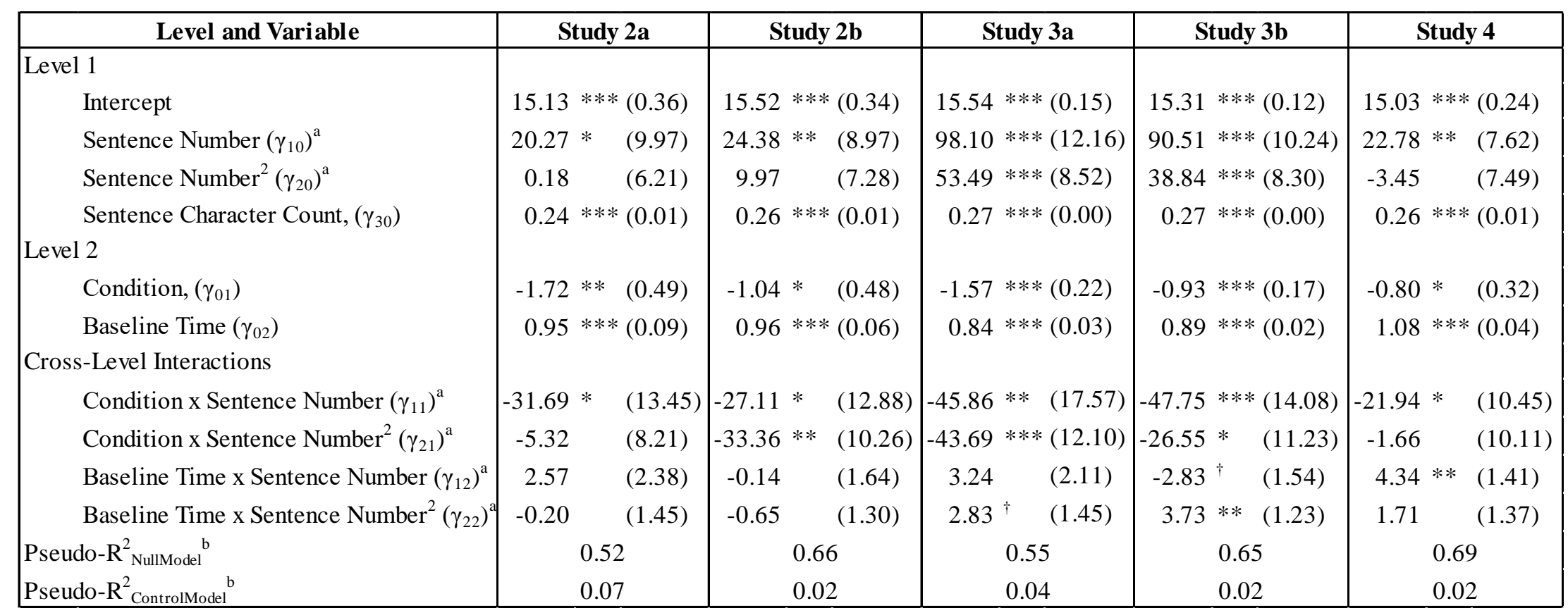

${ }^{\dagger} \mathrm{p}<0.1,{ }^{*} \mathrm{p}<0.05, * * \mathrm{p}<0.01, * * * \mathrm{p}<0.001$

Note. The multilevel model coefficients are reported, with the standard errors in parentheses. The Level 1 model is as follows: Sentence Completion Time $=\beta_{0 j}+\beta_{1 j} *($ Sentence Number $)+\beta_{2 j} *\left(\right.$ Sentence Number $\left.{ }^{2}\right)+\beta_{3 j} *($ Character Count $)+r_{i j}$. The Level 2 Models are as follows: $\beta_{0 j}=\gamma_{00}+\gamma_{01} *($ Condition $)$

$+\gamma_{02} *($ Baseline Time $)+u_{0 j} ; \beta_{1 j}=\gamma_{10}+\gamma_{11} *($ Condition $)+\gamma_{12} *($ Baseline Time $)+u_{1 j} ; \beta_{2 j}=\gamma_{20}+\gamma_{21} *($ Condition $)+\gamma_{22} *($ Baseline Time $)+u_{2 j} ; \beta_{3 j}=\gamma_{30}$. The conditions are coded such that the idle time condition equals 0 , and the no idle time (in Studies 2a-3b) or Internet (in Study 4 ) condition equals 1.

${ }^{a}$ Orthogonal polynomials are used for the linear and quadratic sentence number variables.

b Psuedo-R2 values were calculated using Snjiders and Bosker's (1999) formulas. The 'Null Model' Pseudo-R ${ }^{2}$ value compares the full model to the null model and the 'Control Model' Pseudo- $\mathrm{R}^{2}$ value compares the full model to full model (with all random effects) only excluding the three condition/idle time fixed effects $\left(\gamma_{01}, \gamma_{11}\right.$, and $\left.\gamma_{21}\right)$. 
Table 3. Regression Results Predicting the Number of Errors in Task 2

\begin{tabular}{llllll}
\hline Variable & Study 2a & Study 2b & Study 3a & Study 3b & Study 4 \\
\hline Condition & .037 & -.021 & .024 & .016 & .016 \\
Baseline Wrong & $0.750^{* * *}$ & $0.868^{* * *}$ & $0.788^{* * * *}$ & $0.724 * * *$ & $0.796^{* * *}$ \\
$\mathrm{R}^{2}$ & 0.563 & 0.757 & 0.618 & 0.524 & 0.630 \\
$\mathrm{~F}$ & $28.326^{* * *}$ & $88.803^{* * *}$ & $318.207^{* * *}$ & $218.804 * * *$ & $88.482^{* * *}$ \\
\hline
\end{tabular}

${ }^{\dagger} \mathrm{p}<0.1,{ }^{*} \mathrm{p}<0.05, * * \mathrm{p}<0.01, * * * \mathrm{p}<0.001$

Note. Standardized Coefficients are reported. The idle time condition is coded as 0 , and the no idle time condition [in Study 4, the Internet condition] is coded as 1. 
Figure 1. Study 1: Frequency of Other-caused Idle Time

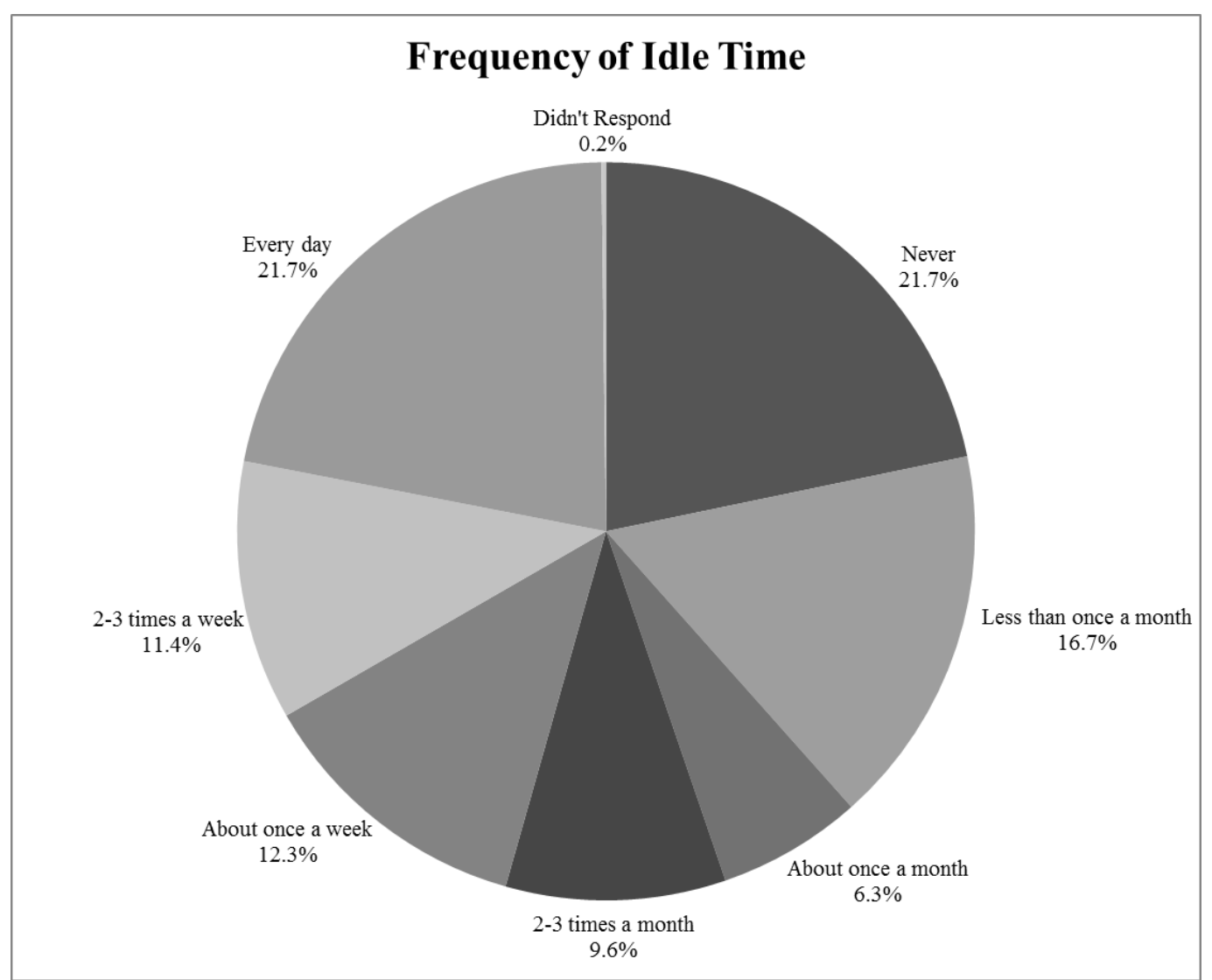


Figure 2. Study 2a \& 2b Deadtime Effect

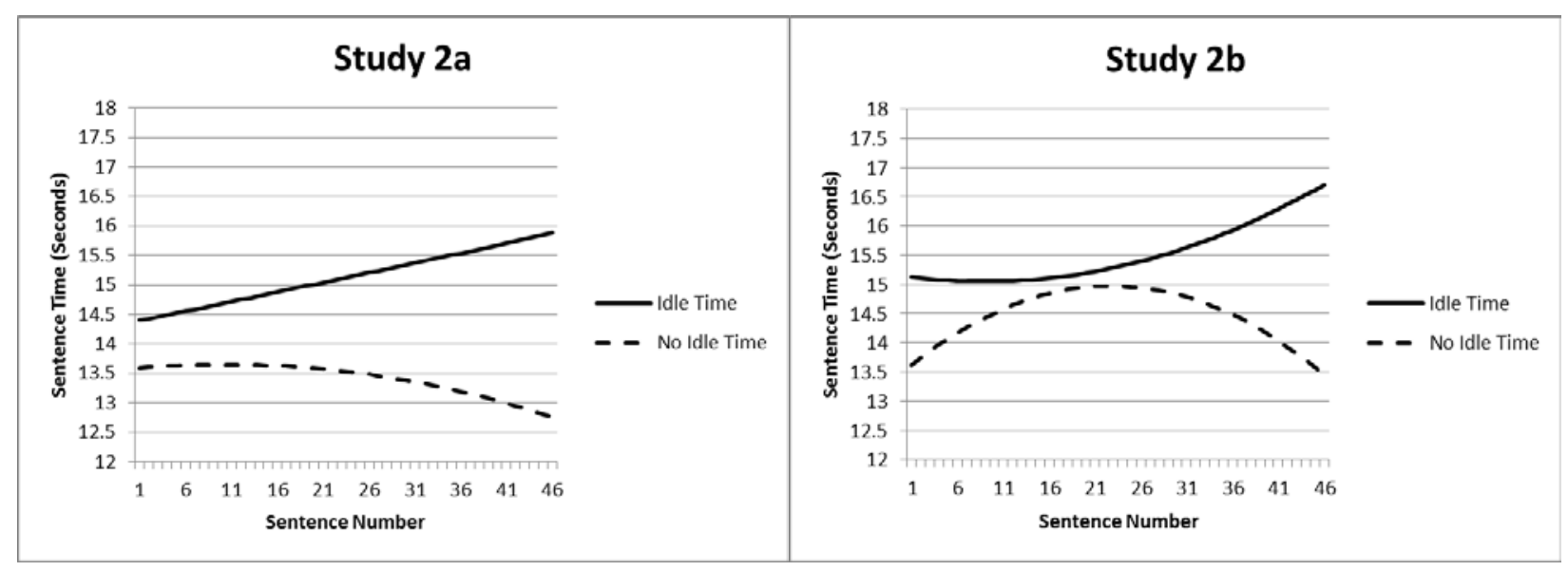

Note. In these studies, the idle time condition significantly $(\mathrm{p}<.05)$ slowed down across the task, but there was no detectable quadratic pacing effect within the idle time condition. Further details of these analyses are provided in Table 2. 
Figure 3. Studies 3a and 3b Deadtime effect

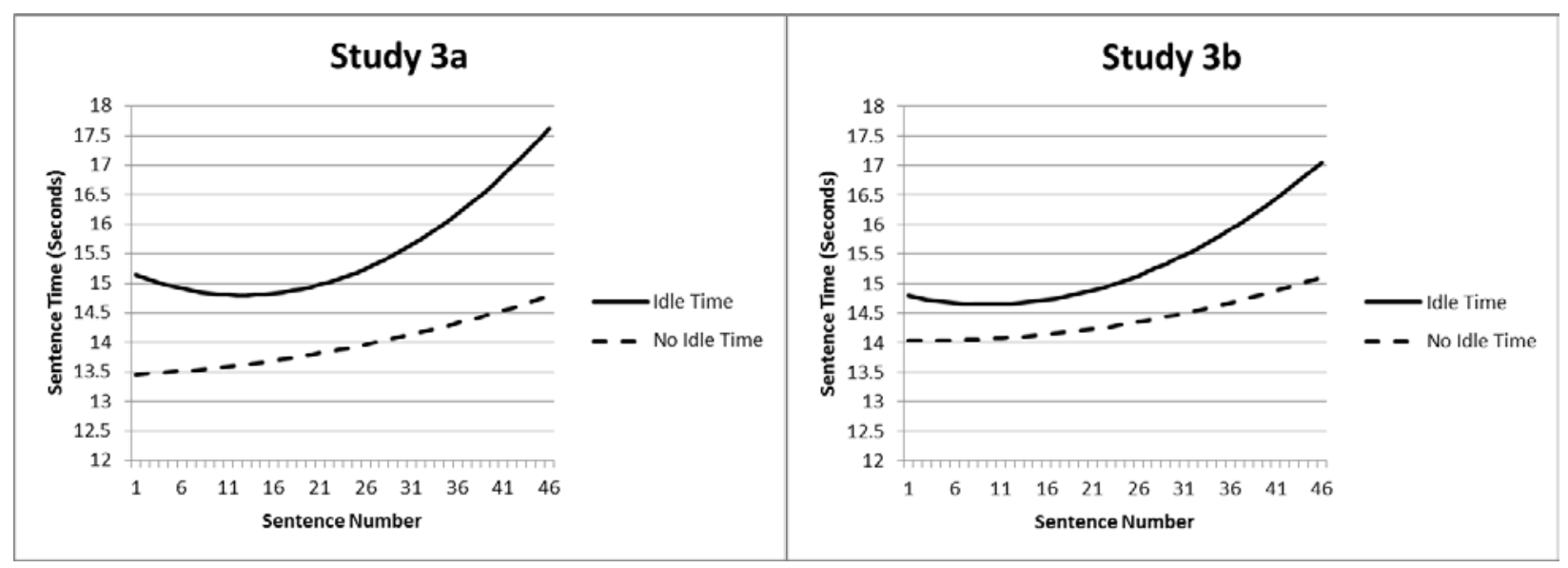

Note. In these studies, the idle time condition slowed down significantly $(\mathrm{p}<.05)$ across the task and there was a significant $(\mathrm{p}<.05)$ quadratic pacing effect within the idle time condition. Further details of these analyses are provided in Table 2. 
Figure 4. Study 4 Deadtime effect

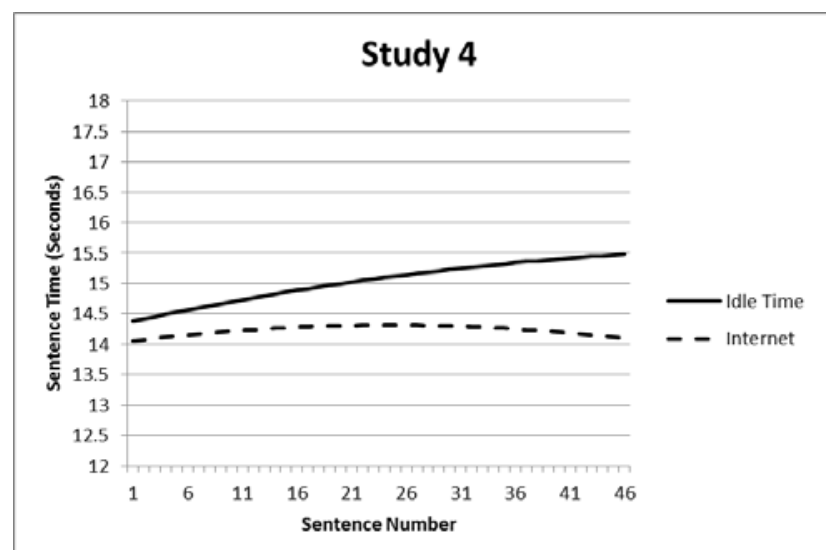

Note. In this study, the idle time condition significantly $(\mathrm{p}<.05)$ slowed down across the task, but there was no detectable quadratic pacing effect within the idle time condition. Further details of these analyses are provided in Table 2. 


\section{REFERENCES}

Ainslie, G. (1992). Picoeconomics: The strategic interaction of successive motivational states within the person. New York, NY: Cambridge University Press.

Amabile, T. M., Mueller, J. S., Simpson, W. B., Hadley, C. N., Kramer, S. J., \& Fleming, L. (2002). Time pressure and creativity in organizations: A longitudinal field study.

Amour, S. (2006). Companies keep an eye on workers' Internet use. USA Today Retrieved October 21, 2013, from http://usatoday30.usatoday.com/tech/news/internetprivacy/2006-02-20internet-abuse_x.htm

Antonides, G., Verhoef, P. C., \& van Aalst, M. (2002). Consumer perception and evaluation of waiting time: A field experiment. Journal of Consumer Psychology, 12(3), 193-202. doi: 10.1207/S15327663jcp1203_02

Arnheiter, E. D., \& Maleyeff, J. (2005). The integration of lean management and Six Sigma. The TQM Magazine, 17(1), 5-18.

Aronson, E., \& Gerard, E. (1966). Beyond Parkinson's law: the effect of excess time on subsequent performance. Journal of Personality and Social Psychology, 3(3), 336.

Askew, K., Buckner, J. E., Taing, M. U., Ilie, A., Bauer, J. A., \& Coovert, M. D. (2014). Explaining cyberloafing: The role of the theory of planned behavior. Computers in Human Behavior, 36, 510-519. doi: 10.1016/j.chb.2014.04.006

Bailenson, J. N., Iyengar, S., Yee, N., \& Collins, N. A. (2008). Facial similarity between voters and candidates causes influence. Public Opinion Quarterly, 72(5), 935-961. doi: 10.1093/poq/nfn054 
Beck, J. W., \& Schmidt, A. M. (2013). State-level goal orientations as mediators of the relationship between time pressure and performance: A longitudinal study. Journal of Applied Psychology, 98(2), 354-363. doi: 10.1037/a0031145

Bliese, P. D., \& Ployhart, R. E. (2002). Growth modeling using random coefficient models: Model building, testing, and illustrations. Organizational Research Methods, 5(4), 362-387. doi: $10.1177 / 109442802237116$

Britton, A., \& Shipley, M. J. (2010). Bored to death? International Journal of Epidemiology, 39(2), 370.

Bryan, J. F., \& Locke, E. A. (1967). Parkinson's law as a goal-setting phenomenon. Organizational Behavior and Human Performance, 2(3), 258-275.

Carlson, D. S., \& Perrewé, P. L. (1999). The role of social support in the stressor-strain relationship: An examination of work-family conflict. Journal of Management, 25(4), 513540. doi: Doi 10.1177/014920639902500403

Chinander, K. R., \& Schweitzer, M. E. (2003). The input bias: The misuse of input information in judgments of outcomes. Organizational Behavior and Human Decision Processes, 91(2), 243-253. doi: 10.1016/S0749-5978(03)00025-6

Connor, C. (2013). Who wastes the most time at work? Forbes Retrieved December 1, 2014, from http://www.forbes.com/sites/cherylsnappconner/2013/09/07/who-wastes-the-most-timeat-work/

Cottrell, N. B., Wack, D. L., Sekerak, G. J., \& Rittle, R. H. (1968). Social facilitation of dominant responses by the presence of an audience and the mere presence of others. Journal of Personality and Social Psychology, 9(3), 245. 
Critchfield, T. S., \& Kollins, S. H. (2001). Temporal discounting: basic research and the analysis of socially important behavior. Journal of Applied Behavior Analysis, 34(1), 101. doi: 10.1901/jaba.2001.34-101

DeVoe, S. E., \& Pfeffer, J. (2011). Time is tight: how higher economic value of time increases feelings of time pressure. Journal of Applied Psychology, 96(4), 665-676. doi: $10.1037 / \mathrm{a} 0022148$

Draper, N. R., Smith, H., \& Pownell, E. (1966). Applied regression analysis (Vol. 3): Wiley New York.

Eisenberg, D., Freed, G. L., Davis, M. M., Singer, D., \& Prosser, L. A. (2011). Valuing health at different ages. Applied Health Economics and Health Policy, 9(3), 149-156.

Elsbach, K. D., Cable, D. M., \& Sherman, J. W. (2010). How passive ‘face time’affects perceptions of employees: Evidence of spontaneous trait inference. Human Relations, 63(6), 735-760. doi: $10.1177 / 0018726709353139$

Elsbach, K. D., \& Hargadon, A. B. (2006). Enhancing creativity through" mindless" work: A framework of workday design. Organization Science, 17(4), 470-483. doi: 10.1287/orsc.1060.0193

Fisher, C. D. (1993). Boredom at work: A neglected concept. Human Relations, 46(3), 395. doi: $10.1177 / 001872679304600305$

Fiske, D. W., \& Maddi, S. R. (1961). Functions of varied experience. Homewood, IL.

Frederick, S., Loewenstein, G., \& O'donoghue, T. (2002). Time discounting and time preference: A critical review. Journal of Economic Literature, 40(2), 351-401. doi: $10.1257 / 002205102320161311$ 
Gardner, D. G. (1986). Activation theory and task design: an empirical test of several new predictions. Journal of Applied Psychology, 71(3), 411. doi: 10.1037/0021-9010.71.3.411

Gersick, C. J. (1988). Time and transition in work teams: Toward a new model of group development. Academy of Management Journal, 31(1), 9-41. doi: 10.2307/256496

Gersick, C. J. (1989). Marking time: Predictable transitions in task groups. Academy of Management Journal, 32(2), 274-309. doi: 10.2307/256363

Gevers, J., Mohammed, S., \& Baytalskaya, N. (2015). The conceptualisation and measurement of pacing styles. Applied Psychology, 64(3), 499-540. doi: 10.1111/apps.12016

Gevers, J. M., Rutte, C. G., \& Van Eerde, W. (2006). Meeting deadlines in work groups: Implicit and explicit mechanisms. Applied Psychology, 55(1), 52-72. doi: 10.1111/j.14640597.2006.00228.x

Green, L., Fristoe, N., \& Myerson, J. (1994). Temporal discounting and preference reversals in choice between delayed outcomes. Psychonomic Bulletin \& Review, 1(3), 383-389. doi: 10.3758/Bf03213979

Green, L., \& Myerson, J. (1996). Exponential versus hyperbolic discounting of delayed outcomes: Risk and waiting time. American Zoologist, 36(4), 496-505.

Green, L., Myerson, J., \& McFadden, E. (1997). Rate of temporal discounting decreases with amount of reward. Memory \& cognition, 25(5), 715-723.

Gustafsson, A., \& Johnson, M. (2003). Competing in a service economy. San Francisco: JosseyBass.

Hackman, J. R., \& Wageman, R. (2005). A theory of team coaching. Academy of Management Review, 30(2), 269-287. doi: 10.5465/Amr.2005.16387885 
Harris, K. M., Schonlau, M., \& Lurie, N. (2009). Surveying a nationally representative internetbased panel to obtain timely estimates of influenza vaccination rates. Vaccine, 27(6), 815818. doi: 10.1016/j.vaccine.2008.11.052

Hofmann, D. A., \& Gavin, M. B. (1998). Centering decisions in hierarchical linear models: Implications for research in organizations. Journal of Management, 24(5), 623-641. doi: 10.1016/S0149-2063(99)80077-4

Houston, M. B., Bettencourt, L. A., \& Wenger, S. (1998). The relationship between waiting in a service queue and evaluations of service quality: a field theory perspective. Psychology \& Marketing, 15(8), 735-753. doi: 10.1002/(Sici)1520-6793(199812)15:8<735::AidMar2>3.0.Co;2-9

Hui, C., Organ, D. W., \& Crocker, K. (1994). Time pressure, Type A syndrome, and organizational citizenship behavior: A laboratory experiment. Psychological reports, 75(1), 199-208. doi: 10.2466/pr0.1994.75.1.199

Jett, Q. R., \& George, J. M. (2003). Work interrupted: A closer look at the role of interruptions in organizational life. Academy of Management Review, 28(3), 494-509.

Jia, H., Jia, R., \& Karau, S. (2013). Cyberloafing and personality: The impact of the Big Five traits and workplace situational factors. Journal of Leadership \& Organizational Studies, 20(3), 1548051813488208. doi: 10.1177/1548051813488208

Kass, S. J., Vodanovich, S. J., \& Callender, A. (2001). State-trait boredom: Relationship to absenteeism, tenure, and job satisfaction. Journal of Business and Psychology, 16(2), 317327. doi: 10.1023/A:1011121503118

Killingsworth, M. A., \& Gilbert, D. T. (2010). A wandering mind is an unhappy mind. Science, 330(6006), 932-932. doi: 10.1126/science.1192439 
Kleinbaum, D., Kupper, L., Nizam, A., \& Rosenberg, E. (2013). Applied regression analysis and other multivariable methods: Nelson Education.

Knight, C., \& Haslam, S. A. (2010). The relative merits of lean, enriched, and empowered offices: an experimental examination of the impact of workspace management strategies on wellbeing and productivity. Journal of Experimental Psychology: Applied, 16(2), 158. doi: $10.1037 / \mathrm{a} 0019292$

König, C. J., \& Kleinmann, M. (2004). Business before pleasure: no strategy for procrastinators? Personality and Individual Differences, 37(5), 1045-1057.

Krafcik, J. F. (1988). Triumph of the lean production system. Sloan Management Review, 30(1), $41-51$.

Latham, G. P., \& Locke, E. A. (1975). Increasing productivity and decreasing time limits: A field replication of Parkinson's law. Journal of Applied Psychology, 60(4), 524-526.

Lay, C. H. (1986). At last, my research article on procrastination. Journal of Research in Personality, 20(4), 474-495. doi: 10.1016/0092-6566(86)90127-3

Lerner, J. S., Gonzalez, R. M., Small, D. A., \& Fischhoff, B. (2003). Effects of fear and anger on perceived risks of terrorism a national field experiment. Psychological Science, 14(2), 144150. doi: $10.1111 / 1467-9280.01433$

Lerner, J. S., Li, Y., \& Weber, E. U. (2012). The financial costs of sadness. Psychological Science, 24(1), 0956797612450302. doi: 10.1177/0956797612450302

Lim, S. G.-S., \& Murnighan, J. K. (1994). Phases, deadlines, and the bargaining process. Organizational Behavior and Human Decision Processes, 58(2), 153-171. doi: 10.1006/obhd.1994.1032 
Lim, V. K. G. (2002). The IT way of loafing on the job: cyberloafing, neutralizing and organizational justice. Journal of Organizational Behavior, 23(5), 675-694. doi: 10.1002/job.161

Loukidou, L., Loan Clarke, J., \& Daniels, K. (2009). Boredom in the workplace: More than monotonous tasks. International Journal of Management Reviews, 11(4), 381-405. doi: 10.1111/j.1468-2370.2009.00267.x

Malachowski, D. (2005, December 1, 2014). Americans waste more than 2 hours a day at work, costing companies $\$ 759$ billion a year, according to salary.com and america online survey. Business Wire Retrieved January 15, 2012, from http://www.businesswire.com/news/home/20050711005088/en/Americans-Waste-2Hours-Day-Work-Costing

Mantell, R. (2011). How to ease your workload. Wall Street Journal Retrieved July 10, 2013, from http://online.wsj.com/article/SB10001424052748703988504576295994157021046.html

Mateyka, J. P., \& Rapino, M. A. (2012). Home-based workers in the United States: 2010 Household Economic Studies. Retrieved from

May 2014 national occupational employment and wage estimates: United States. (2014). Retrieved October 7, 2015, from Bureau of Labor Statistics http://www.bls.gov/oes/current/oes_nat.htm

McClure, S. M., Ericson, K. M., Laibson, D. I., Loewenstein, G., \& Cohen, J. D. (2007). Time discounting for primary rewards. The Journal of Neuroscience, 27(21), 5796-5804. doi: 10.1523/JNEUROSCI.4246-06.2007 
Mitchell, T. R., Harman, W. S., Lee, T. W., \& Lee, D.-Y. (2008). Self regulation and multiple deadline goals Work motivation: Past, present, and future (pp. 197-232).

Mohammed, S., \& Harrison, D. A. (2013). The clocks that time us are not the same: A theory of temporal diversity, task characteristics, and performance in teams. Organizational behavior and human decision processes, 122(2), 244-256.

Moore, D. A., \& Tenney, E. R. (2012). Time pressure, performance, and productivity. Research on Managing Groups and Teams, 15, 305-326. doi: 10.1108/S15340856(2012)0000015015

Nieuwenhuis, M., Knight, C., Postmes, T., \& Haslam, S. A. (2014). The relative benefits of green versus lean office space: Three field experiments. Journal of Experimental Psychology: Applied, 20(3), 199. doi: 10.1037/xap0000024

O'Donoghue, T., \& Rabin, M. (1999). Incentives for procrastinators. Quarterly Journal of Economics, 114(3), 769-816. doi: 10.1162/003355399556142

O'Hanlon, J. F. (1981). Boredom: Practical consequences and a theory. Acta Psychologica, 49(1), 53-82.

Parkinson, C. N. (1957). Parkinson's Law and Other Studies in Administration. Boston: Houghton Mifflin.

Pfeffer, J., \& Salancik, G. R. (1978). The external control of organizations: A resource dependence approach. NY: Harper and Row Publishers.

Pierro, A., Giacomantonio, M., Pica, G., Kruglanski, A. W., \& Higgins, E. T. (2011). On the psychology of time in action: regulatory mode orientations and procrastination. Journal of Personality and Social Psychology, 101(6), 1317. doi: 10.1037/a0025943 
Ployhart, R. E., \& Vandenberg, R. J. (2010). Longitudinal research: The theory, design, and analysis of change. Journal of Management, 36(1), 94-120. doi: $10.1177 / 0149206309352110$

Quast, L. (2012). In Project Overload? How To Say No to Your Boss. Forbes Retrieved July 10, 2013, from http://www.forbes.com/sites/lisaquast/2012/04/30/help-im-in-projectoverload-tips-for-managing-your-workload-and-saying-no-to-your-boss/

R Core Team. (2014). R: A Language and Environment for Statistical Computing. Vienna, Australia: R Foundation for Statistical Computing. Retrieved from http://www.Rproject.org/

Rachlin, H., Raineri, A., \& Cross, D. (1991). Subjective probability and delay. Journal of the Experimental Analysis of Behavior, 55(2), 233. doi: 10.1901/jeab.1991.55-233

Robert, M. Y., \& John, D. (1908). The relation of strength of stimulus to rapidity of habitformation. Journal of Comparative Neurology and Psychology, 18, 459-482.

Roth, A. E., Murnighan, J. K., \& Schoumaker, F. (1988). The deadline effect in bargaining: Some experimental evidence. The American Economic Review, 78(4), 806-823.

Samuelson, P. A. (1937). A note on measurement of utility. The Review of Economic Studies, 4(2), 155-161.

Schlosberg, H. (1954). Three dimensions of emotion. Psychological review, 61(2), 81.

Scott, W. E. (1966). Activation theory and task design. Organizational Behavior and Human Performance, 1(1), 3-30. doi: 10.1016/0030-5073(66)90003-1

Seers, A., McGee, G. W., Serey, T. T., \& Graen, G. B. (1983). The interaction of job stress and social support: A strong inference investigation. Academy of Management Journal, 26(2), 273-284. doi: 10.2307/255975 
Seers, A., \& Woodruff, S. (1997). Temporal pacing in task forces: Group development or deadline pressure? Journal of Management, 23(2), 169-187. doi: 10.1016/S0149-2063(97)90042-8

Seery, M. D., Holman, E. A., \& Silver, R. C. (2010). Whatever does not kill us: cumulative lifetime adversity, vulnerability, and resilience. Journal of Personality and Social Psychology, 99(6), 1025.

Shah, R., \& Ward, P. T. (2007). Defining and developing measures of lean production. Journal of Operations Management, 25(4), 785-805. doi: 10.1016/j.jom.2007.01.019

Snjiders, T., \& Bosker, R. (1999). Multilevel analysis: An introduction to basic and advanced multilevel modeling: London: Sage.

Sonnentag, S. (2001). Work, recovery activities, and individual well-being: a diary study. Journal of Occupational Health Psychology, 6(3), 196.

Spector, P. E., Fox, S., Penney, L. M., Bruursema, K., Goh, A., \& Kessler, S. (2006). The dimensionality of counterproductivity: Are all counterproductive behaviors created equal? Journal of Vocational Behavior, 68(3), 446-460.

Steel, P. (2007). The nature of procrastination: a meta-analytic and theoretical review of quintessential self-regulatory failure. Psychological Bulletin, 133(1), 65. doi: 10.1037/0033-2909.133.1.65

Steel, P., \& König, C. J. (2006). Integrating theories of motivation. Academy of Management Review, 31(4), 889-913. doi: 10.5465/Amr.2006.22527462

Taylor, S. (1994). Waiting for service: the relationship between delays and evaluations of service. The Journal of Marketing, 58(2), 56-69. doi: 10.2307/1252269

Thaler, R. H. (1998). Some Empirical Evidence on Dynamic Inconsistency. Economic Letters, 8(3), 201-207. 
Tom, G., \& Lucey, S. (1995). Waiting time delays and customer satisfaction in supermarkets. Journal of Services Marketing, 9(5), 20-29.

Trope, Y., \& Liberman, N. (2000). Temporal construal and time-dependent changes in preference. Journal of Personality and Social Psychology, 79(6), 876.

Trougakos, J., Hideg, I., Cheng, B., \& Beal, D. (2013). Lunch breaks unpacked: The role of autonomy as a moderator of recovery during lunch. Academy of Management Journal.

Waller, M. J., Zellmer-Bruhn, M. E., \& Giambatista, R. C. (2002). Watching the clock: Group pacing behavior under dynamic deadlines. Academy of Management Journal, 45(5), 10461055. doi: 10.2307/3069329

Wilson, T. D., Reinhard, D. A., Westgate, E. C., Gilbert, D. T., Ellerbeck, N., Hahn, C., ... Shaked, A. (2014). Just think: The challenges of the disengaged mind. Science, 345(6192), 75-77. doi: $10.1126 /$ science. 1250830

Woodman, R. W., Sawyer, J. E., \& Griffin, R. W. (1993). Toward a theory of organizational creativity. Academy of Management Review, 18(2), 293-321. doi: 10.2307/258761

Wooléver, A. (1893). Encyclopaedia of quotations: a treasury of wisdom, wit and humor, odd comparisons and proverbs. Philadelphia: David McKay. 